\title{
Understanding the Dynamics of the US External Position
}

First Draft:July 2010

Last Draft: January 2011

\author{
Martin D. D. Evans \\ Georgetown University and NBER \\ Department of Economics \\ Washington DC 20057 \\ Tel: (202) 687-1570 \\ evansm1@georgetown.edu
}

Alberto Fuertes

Georgetown University

Department of Economics

Washington DC 20057

\begin{abstract}
This paper studies the dynamics of the U.S. external position for the past 35 years, and examines alternative paths for future external adjustment. We develop a new present value expression for the external position that embeds the restrictions of international solvency and can be easily empirically evaluated with time series methods. Our empirical model accounts for almost all the variations in the U.S. external position between 1973 and 2008. We estimate that most of the quarter-by-quarter changes in the U.S. external position over this period are due to news about future returns and trade flows, but over long horizons the changes reflect prior expectations about how the U.S. would meet its international financial obligations. Importantly, we identify the expectations embedded in the current U.S. external position that contain relevant information about the future adjustment paths. These expectations indicate that the half-lives for future adjustment paths towards U.S. external balance are at least 13 years and involve a significant real depreciation of the dollar.
\end{abstract}

Keywords: Capital Flows, External Imbalances, International Debt, International Solvency JEL Codes: F31, F32, F34 


\section{Introduction}

Since the demise of the Bretton Woods System, there has been a sustained and significant deterioration in the U.S. net external asset position (i.e., the difference between US foreign assets and U.S. foreign liabilities). In 1973 the net external asset position was approximately equal to five percent of GDP. By 2008 the position had deteriorated to the point where foreign liabilities exceeded foreign assets by roughly thirty percent of GDP. Figure 1 shows that some of this deterioration is associated with the onset of the 2008 crisis. However, it is also clear that there has been a strong secular decline in the U.S. net external position since the late 1970's. In this paper, we empirically examine the contribution of the different factors driving the U.S. external position over the past 35 years. We then use the results of this analysis to study how the U.S. must adjust in the future to meet its international financial obligations.

At one level, the reason for the deterioration in the U.S. external position appears obvious: the U.S. systemically ran current account deficits that were largely financed by international borrowing. As Figure 1 shows, the U.S. accumulated foreign liabilities at a consistently faster rate than foreign assets for most of the last three decades. Of course, this "explanation" represents little more than accounting. It does not address the deeper questions of why the U.S. was able to accumulate international liabilities far in excess of its international asset holdings, and how the net external position will be brought into balance in the future. These are the questions we wish to address.

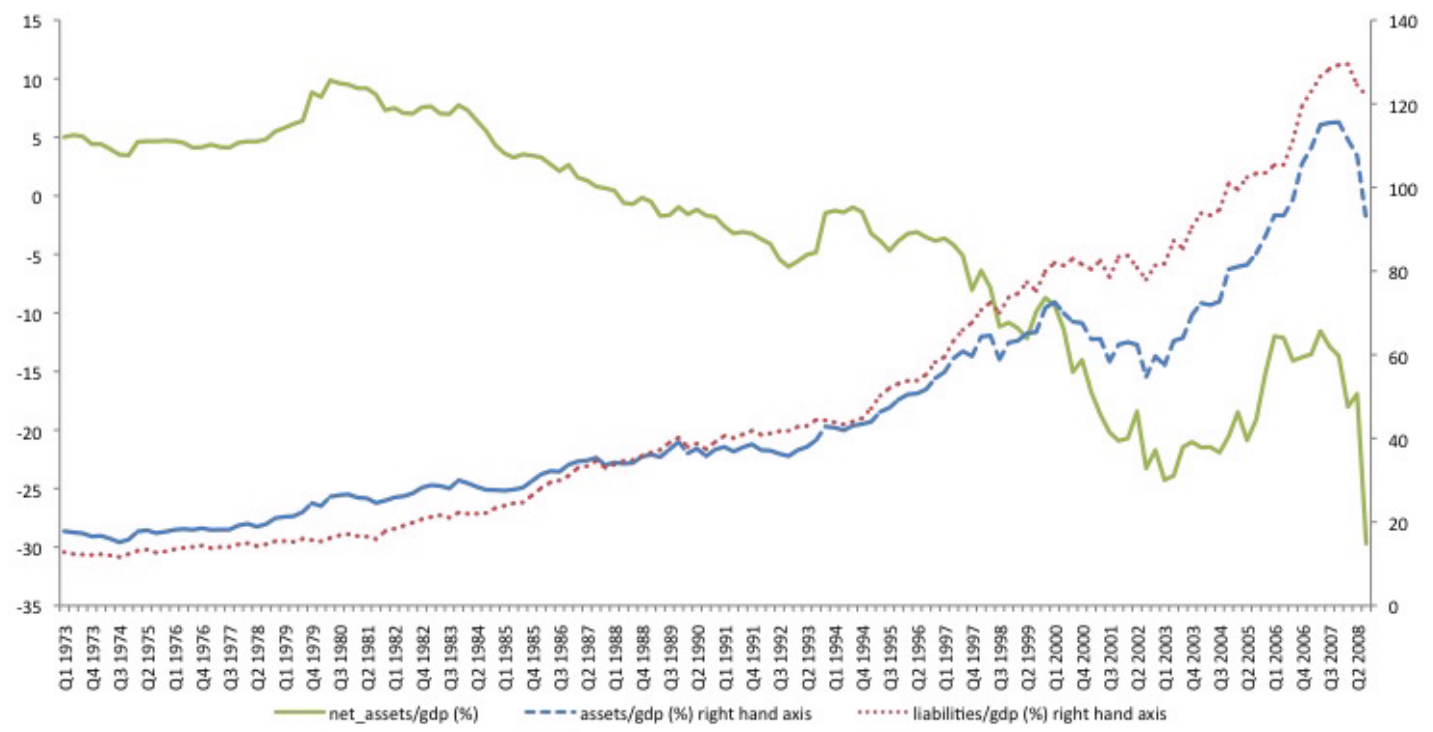

Figure 1: The U.S. External Position and its Components

Our starting point is the accounting identity that links the evolution of U.S. foreign assets and liabilities to exports and imports. This identity implies that the net external position at a point in time reflects expectations concerning the future course of exports, imports, the returns on foreign assets and liabilities, and the likelihood of default. This link between expectations and the current net external position is not an artifact of a particular economic model; it simply reflects the implications of dynamic consistency. When the U.S. accumulates foreign liabilities in excess of its assets, there must be an expectation that the international debt will ultimately be repaid using the proceeds from future net exports and/or returns on foreign assets, or that the U.S. will eventually default. There are simply no other possibilities. Our analysis is based on 
the widely-accepted premise that the perceived likelihood of default by the U.S. has been negligible for the past 35 years. Under this premise, the deterioration in the U.S. external position is fully attributable to changing expectations concerning future trade flows and returns. Our goal, therefore, is to identify how these expectations have changed, and what they imply for the future adjustment of the U.S. external position.

To illustrate our approach, consider the accounting identity linking U.S. foreign assets, liabilities, exports and imports:

$$
F A_{t}-F L_{t}=\mathfrak{X}_{t}-\mathfrak{M}_{t}-R_{t}^{\mathrm{FL}} F L_{t-1}+R_{t}^{\mathrm{FA}} F A_{t-1} .
$$

Here $F A_{t}$ and $F L_{t}$ denote the value of U.S. foreign assets and liabilities at the end of period $t$, while $\mathfrak{X}_{\mathfrak{t}}$ and $\mathfrak{M}_{t}$ represent the flow of U.S. exports and imports during period $t$, all measured in terms of the U.S. consumption index. The (gross) real return on foreign assets and liabilities between the end of periods $t-1$ and $t$ are denoted by $R_{t}^{\mathrm{FA}}$ and $R_{t}^{\mathrm{FL}}$, respectively. Re-arranging this equation and iterating forward, gives

$$
F A_{t}-F L_{t}=-\sum_{i=1}^{\infty} \mathfrak{D}_{t+i}^{-1}\left[\mathfrak{X}_{\mathfrak{t}+\mathfrak{i}}-\mathfrak{M}_{t+i}+\left(R_{t+i}^{\mathrm{FA}}-R_{t+i}^{\mathrm{FL}}\right) F A_{t+i-1}\right]-\lim _{i \rightarrow \infty} \mathfrak{D}_{t+i}^{-1}\left(F L_{t+i}-F A_{t+i}\right),
$$

where $\mathfrak{D}_{t+i}=\prod_{j=1}^{i} R_{t+j}^{\mathrm{FL}}$ is the discount rate. The first term on the right of equation (2) is the present value of net exports, $\mathfrak{X}_{t}-\mathfrak{M}_{t}$, and the net interest income on foreign assets, $\left(R_{t}^{\mathrm{FA}}-R_{t}^{\mathrm{FL}}\right) F A_{t-1}$. The second term identifies the present value of the future US international indebtedness as the horizon rises without limit. This term must be equal to zero to rule out Ponzi-schemes. Imposing this no-Ponzi condition and taking expectations conditional on period- $t$ information $\Omega_{t}$, that includes the value of $F A_{t}-F L_{t}$, gives

$$
F A_{t}-F L_{t}=-\mathbb{E}_{t} \sum_{i=1}^{\infty} \mathfrak{D}_{t+i}^{-1}\left[\mathfrak{X}_{t+i}-\mathfrak{M}_{t+i}+\left(R_{t+i}^{\mathrm{FA}}-R_{t+i}^{\mathrm{FL}}\right) F A_{t+i-1}\right]
$$

Equation (3) shows how dynamic consistency links the current U.S. external position, $F A_{t}-F L_{t}$, to expectations about the future paths of exports, imports, and the returns of foreign assets and liabilities in a world where the U.S. fully honors its international debts. It implies that any deterioration in the U.S. net external position must be associated with an upward revision in the expected path for future net exports, or net income on foreign assets, or a fall in the discount rate, $\mathfrak{D}_{t+i}$, or some combination of the three. In other words, any fall in $F A_{t}-F L_{t}$ must be accompanied by a new set of expectations concerning how the U.S. will honor its larger international obligations in the future.

Equation (3) provides a new perspective on the secular deterioration in the U.S. external position shown in Figure 1. In particular, it appears that over the last 35 years there has been growing optimism about the ability of the U.S. to run future large trade surpluses, earn high future returns on foreign assets, and/or pay low future returns on foreign liabilities. This is an important perspective, but it only provides limited information on how the U.S. net external position will ultimately be brought into balance. The first task of this paper is to empirically estimate how expectations concerning future trade flows and returns have separately been revised as the U.S. external position has deteriorated. We will then use these estimates to examine alternative adjustment paths that will bring the U.S. external position back into balance.

The key step in our analysis is to develop an alternative to equation (3) that embeds the solvency restrictions implied by dynamic consistency without the nonlinearities involving future returns, net exports and foreign assets. For this purpose we develop a log-linear approximation that accurately tracks the dynamics 
of U.S. foreign assets and liabilities implied by the accounting identity in equation (1). This approximation is then used to derive a simple present value expression for the U.S. external position that can be empirically evaluated with standard time series methods. Specifically, we use the time series methods first developed by Campbell and Shiller (1987) to decompose variations in the U.S. external position into components associated with expectations of future exports, imports and the returns on foreign assets and liabilities.

Our analysis produces several striking results: First, the model estimates account for almost all the sample variations in the U.S. external position between 1973:I and 2008:III. Over this period we estimate that revisions in expectations concerning future trade flows, the so-called trade channel, account for 46 percent of the variance in the U.S. external position. Revisions in expectations concerning future returns on U.S. foreign assets and liabilities, the valuation channel, account for the remaining 54 percent. These results cast doubt on the conventional view that the U.S. must ultimately meet its international obligations exclusively via the trade channel, (i.e., solely via a dramatic improvement in net exports).

Second, we use the model estimates to examine how the secular deterioration in the U.S. external position squares with the international solvency constraint implied by dynamic consistency in equation (3). We find that most of the variance in quarter-by-quarter changes in the U.S. external position reflect news about future returns and trade flows, with news about future returns dominating news about future trade flows. The picture is rather different over long horizons. In particular, 25 percent of the variance of 10-year changes in the U.S. external position are predictable and reflect prior expectations about how the U.S. will meet it international obligations. These expectations are masked by the secular deterioration in the U.S. external position shown in Figure 1. Nevertheless, they indicate that the expectations embedded in the current U.S. external position contain relevant information about future adjustment paths over long horizons. Our model estimates imply that trade flows account for approximately 46 percent of this adjustment process, and returns the remaining 54 percent.

Third, we use our model estimates to compute alternative adjustment paths for the U.S. external position. Specifically, we calculate the half lives for the adjustment paths consistent with the expectations concerning future trade flows and returns that are embedded in the 2008:III U.S. external position. These calculations provide estimates of how quickly the U.S. would pay down its international debt in the absence of future news concerning trade flows and returns. When adjustment occurs via both the trade and valuation channels, we estimate the half life to be 13 years. Our results also highlight the importance of both the trade and valuation channels in the expected adjustment process. Expectations about future trade flows and returns imply that the U.S. would never return to external balance if adjustment could only take place via either the trade or valuation channels.

Our model does not identify the economic mechanism that drives expectations concerning future trade flows and returns. However, standard theoretical models suggest that these expectations must also embed forecasts for the future depreciation of the dollar. Consistent with this idea, we find that variations in the U.S. external position have an economically significant degree of forecasting power for future dollar depreciation rates (both multi- and bilateral rates) at horizons of one to four quarters. We then use these exchange-rate forecasts to compute projections for the real value of the U.S. dollar along the expected adjustment path for the U.S. external position. These calculations show that expected external adjustment over the next decade is associated with an anticipated real deprecation of the dollar of approximately 30 percent on a trade-wieghted basis.

Our research methodology is most closely related to the work of Gourinchas and Rey (2007) (hereafter 
G\&R). They use approximation methods to develop an estimable model for the cyclical component of the U.S. external position. This approach is similar to ours in the sense that it relates changes in the U.S. external position to changes in expectations about future trade flows and returns. However, in contrast to G\&R, we model variations in the entire U.S. external position, not just the cyclical component. This difference is important for at least two reasons: First, as Figure 1 makes clear, there has been a secular deterioration in the U.S. external position since the late 1970s, so a model focusing on cyclical variations can only provide an incomplete picture of the expectational changes that have accompanied this deterioration. Second, if we are to make reliable inferences about the future adjustment path of the U.S. external position from current expectations, these expectations need to be (dynamically) consistent with the total current position, not its cyclical component.

Our work is also related to a larger literature examining the role of valuation effects in external adjustment. In a series of papers, Lane and Milesi-Ferretti have highlighted the aggregate role of valuation effects in driving net foreign asset positions (see Lane and Milesi-Ferretti 2001 and 2007). Our results compliment this work by showing that expectations of higher future real returns on US foreign asset than on future foreign liabilities have been central to squaring the long-term deterioration of the U.S. external position with the constraints of international solvency. Indeed, our model estimates imply that the valuation channel has been an even more important stabilizing influence on the U.S. external position that suggested by the results in G\&R. We should stress that this finding is not attributable to the mis-measurement of returns. Curcuru, Dvorak, and Warnock (2008) argue that the returns on U.S. foreign asset and liability portfolios used in earlier studies were biased upward, and, as a result, the importance of the valuation channel was overstated. The returns we use are comparable to those constructed by Curcuru et al. (2008), so our findings concerning the importance of the valuation channel cannot be attributed to these data problems. Finally, our analysis of how external adjustment is likely to affect the value of the dollar builds on earlier work by Tille (2003), Lane and Milesi-Ferretti (2004) and others.

The paper is structured as follows: We begin by deriving the log-linear approximation to the dynamics of U.S. foreign assets and liabilities and assessing its accuracy. In Section 3 we develop the present value expression for the U.S. external position and study its implications for the joint dynamics of foreign assets, liabilities, trade flows and returns. Here we also describe the time-series methods used to estimate the trade and valuation channels. Section 4 presents the estimation results and our analysis of the future paths for U.S. external adjustment. Section 5 concludes.

\section{Foreign Asset and Liability Dynamics}

Our analysis utilizes an approximation that accurately tracks the dynamics of U.S. external position given the behavior of foreign assets, liabilities, trade flows and returns implied by the accounting identity in equation (1). We will use this approximation below to derive a present value expression for the U.S. external position that embeds the solvency restriction in equation (3) without the nonlinearities involving future returns, net exports and foreign assets. The expression is a useful analytical tool for thinking about the evolution of the

U.S. external position and the characteristics of possible future adjustment paths. It also forms the basis for our empirical model.

The approximation is based on the observation that the identity in equation (1) can be thought of as 
combining two sets of dynamics: one for U.S. foreign assets and one for liabilities:

$$
\begin{aligned}
F A_{t} & =R_{t}^{\mathrm{FA}} F A_{t-1}-\mathfrak{M}_{t} \quad \text { and } \\
F L_{t} & =R_{t}^{\mathrm{FL}} F L_{t-1}-\mathfrak{X}_{t} .
\end{aligned}
$$

These equation would determine dynamics of assets and liabilities in a world where imports are paid for by selling foreign assets, and the proceeds from exports are used to pay down existing foreign liabilities. Our approximation method essentially combines log-linear approximations for these two equations, while allowing for the fact that (1) permits greater fungibility between the payments associated with trade flows and the dynamics of foreign assets and liabilities. For example, imports can be paid for with the proceeds of exports, or liabilities reduced by the sale of assets. This approach has two advantages. First, it permits the use of standard log-linearization methods without regard to the sign of net exports, or the net foreign asset position. Second, and more importantly, our method can accommodate the trends in U.S. exports, imports, foreign assets and liabilities. G\&R note that all four variables grew significantly faster than U.S. household wealth between 1952 and 2004 ( Figure 1 shows similar trends in the ratios of assets and liabilities to GDP), so standard approximations around fixed ratios will be inaccurate. To avoid this problem G\&R focus on the adjustment process around these trends. In contrast, our method accommodates the trends in these ratios without sacrificing approximation accuracy.

Our approximation involves three steps: First, we rewrite (1) as

$$
f a_{t}=r_{t}^{\mathrm{FA}}+f a_{t-1}+\ln \left(1-\exp \left(m_{t}-r_{t}^{\mathrm{FA}}-f a_{t-1}\right)+\Re_{t}\right),
$$

where

$$
\Re_{t}=\exp \left(f l_{t}-r_{t}^{\mathrm{FA}}-f a_{t-1}\right)+\exp \left(x_{t}-r_{t}^{\mathrm{FA}}-f a_{t-1}\right)-\exp \left(r_{t}^{\mathrm{FL}}-r_{t}^{\mathrm{FA}}+f l_{t-1}-f a_{t-1}\right) .
$$

Here lowercase letters denote natural logs of their uppercase counterparts, e.g., $f a_{t}=\ln F A_{t}$. We then take a first-order Taylor approximation to the last term term on the RHS of (5) around the point where $\Re_{t}=0$ and $1-\left(\mathfrak{M}_{t} / R_{t}^{\mathrm{FA}} F A_{t-1}\right)=\rho \in(0,1)$. This produces

$$
f a_{t}=r_{t}^{\mathrm{FA}}+f a_{t-1}-\frac{1-\rho}{\rho}\left(m_{t}-r_{t}^{\mathrm{FA}}-f a_{t-1}\right)+\frac{1}{\rho} \Re_{t}+k,
$$

where $k \equiv \ln (\rho)+\frac{1-\rho}{\rho} \ln (1-\rho)$.

Equation (6) provides us with the approximate dynamics of U.S. foreign assets embedded in the identity (1). There are two possible sources of approximation error. The first comes from variations in the import to asset ratio, $\mathfrak{M}_{t} / R_{t}^{\mathrm{FA}} F A_{t-1}$. If this ratio equals $1-\rho$, (4a) implies that $f a_{t}=r_{t}^{\mathrm{FA}}+f a_{t-1}+\ln \rho$, so (6) would accurately represent the dynamics of U.S. foreign assets if the fungibility restrictions behind (4) held true. The second source of error comes from variations in $\Re_{t}$. $\Re_{t}=0$ when U.S. assets and liabilities follow (4), so variations in $\Re_{t}$ reflect fungibility between the payments associated with trade flows and the dynamics of foreign assets and liabilities allowed by (1).

In the second step we approximate the dynamics of the U.S. foreign liabilities. For this purpose, we 
rewrite the definition of $\Re_{t}$ as

$$
\exp \left(f l_{t}-r_{t}^{\mathrm{FA}}-f a_{t-1}\right)=\left(1-\exp \left(x_{t}-r_{t}^{\mathrm{FA}}-f a_{t-1}\right)\right) \exp \left(r_{t}^{\mathrm{FL}}-r_{t}^{\mathrm{FA}}+f l_{t-1}-f a_{t-1}\right)+\Re_{t}
$$

and take logs:

$$
f l_{t}-r_{t}^{\mathrm{FA}}-f a_{t-1}=\ln \left\{\left(1-\exp \left(x_{t}-r_{t}^{\mathrm{FA}}-f a_{t-1}\right)\right) \exp \left(r_{t}^{\mathrm{FL}}-r_{t}^{\mathrm{FA}}+f l_{t-1}-f a_{t-1}\right)+\Re_{t}\right\} .
$$

We then take another first-order Taylor approximation to the term on the RHS around the point where $1-\left(\mathfrak{X}_{t} / R_{t}^{\mathrm{FL}} F L_{t-1}\right)=\rho, \Re_{t}=0$ and $R_{t}^{\mathrm{FA}} F A_{t-1} / R_{t}^{\mathrm{FL}} F L_{t-1}=1$. After some simplification, this produces

$$
f l_{t}=r_{t}^{\mathrm{FL}}+f l_{t-1}-\frac{1-\rho}{\rho}\left(x_{t}-r_{t}^{\mathrm{FL}}-f l_{t-1}\right)+\frac{1}{\rho} \Re_{t}+k .
$$

Here there are three sources of approximation error: variations in $\Re_{t}$; the export to liability ratio, $\mathfrak{X}_{t} / R_{t}^{\mathrm{FL}} F L_{t-1}$; and asset to liability ratio, $R_{t}^{\mathrm{FA}} F A_{t-1} / R_{t}^{\mathrm{FL}} F L_{t-1}$.

In the final step we combine (6) and (7) to eliminate $\Re_{t}$. For this purpose, let $N F A_{t}=R_{t}^{\mathrm{FA}} F A_{t-1} / R_{t}^{\mathrm{FL}} F L_{t-1}$ define the ratio of U.S. foreign assets to liabilities at the beginning of period $t$. (Recall that $F A_{t}$ and $F L_{t}$ denote the real value of U.S. foreign assets and liabilities at the the end of period $t$, while $R_{t}^{\mathrm{FA}}$ and $R_{t}^{\mathrm{FL}}$ are the returns on these portfolio between the start of periods $t-1$ and $t$.) Combining this definition with (6) and (7) produces

$$
n f a_{t}=r_{t}^{\mathrm{NFA}}+\frac{1-\rho}{\rho} n x_{t-1}+\frac{1}{\rho} n f a_{t-1}
$$

where $n x_{t}=x_{t}-m_{t}$ is the log ratio of exports to imports (hereafter "net exports"), and $r_{t}^{\mathrm{NFA}}=r_{t}^{\mathrm{FA}}-r_{t}^{\mathrm{FL}}$ is the return differential between foreign assets and liabilities. It is convenient to rewrite this expression in terms of a new variable, $n x a_{t}=n f a_{t}+n x_{t}$ :

$$
n x a_{t}=r_{t}^{\mathrm{NFA}}+\Delta n x_{t}+\frac{1}{\rho} n x a_{t-1}
$$

where $\Delta n x_{t}=n x_{t}-n x_{t-1}$ is the growth in net exports. This equation approximates the joint dynamics of U.S. foreign assets, liabilities, exports, imports and returns around the point where $\mathfrak{M}_{t} / R_{t}^{\mathrm{FA}} F A_{t-1}=$ $\mathfrak{X}_{t} / R_{t}^{\mathrm{FL}} F L_{t-1}=1-\rho, \Re_{t}=0$ and $N F A_{t}=1$. It is easy to check that this point is where the U.S. is in external balance with net exports equal to zero and the value of foreign assets is equal to the value of foreign liabilities.

We will use $n x a_{t}$ as our measure of the U.S. external position. It comprises the sum of the log ratio of U.S. assets to liabilities at the beginning of period $t, \ln \left(N F A_{t}\right)$, and the $\log$ ratio of exports to imports, $\ln \left(\mathfrak{X}_{t} / \mathfrak{M}_{t}\right)$. Intuitively, our measure compares the current external asset position at the beginning of each period with the balance of trade during the period. The external position deteriorates when there is a fall in net exports or a fall in the return on foreign assets relative to foreign liabilities, or some combination of the two. As we shall see, the requirements of international solvency imply a particularly simply relation between $n x a_{t}$ and expectations concerning future return differentials, $r_{t}^{\mathrm{NFA}}$ and the growth in net exports, $\Delta n x_{t}$.

The dynamic relation between U.S. foreign assets, liabilities, exports, imports and returns implied by the accounting identity in (1) could induce variations in $n x a_{t}$ that are not captured by (8) because the latter equation omits two approximation errors. The first error comes from the approximation in (6), the second 


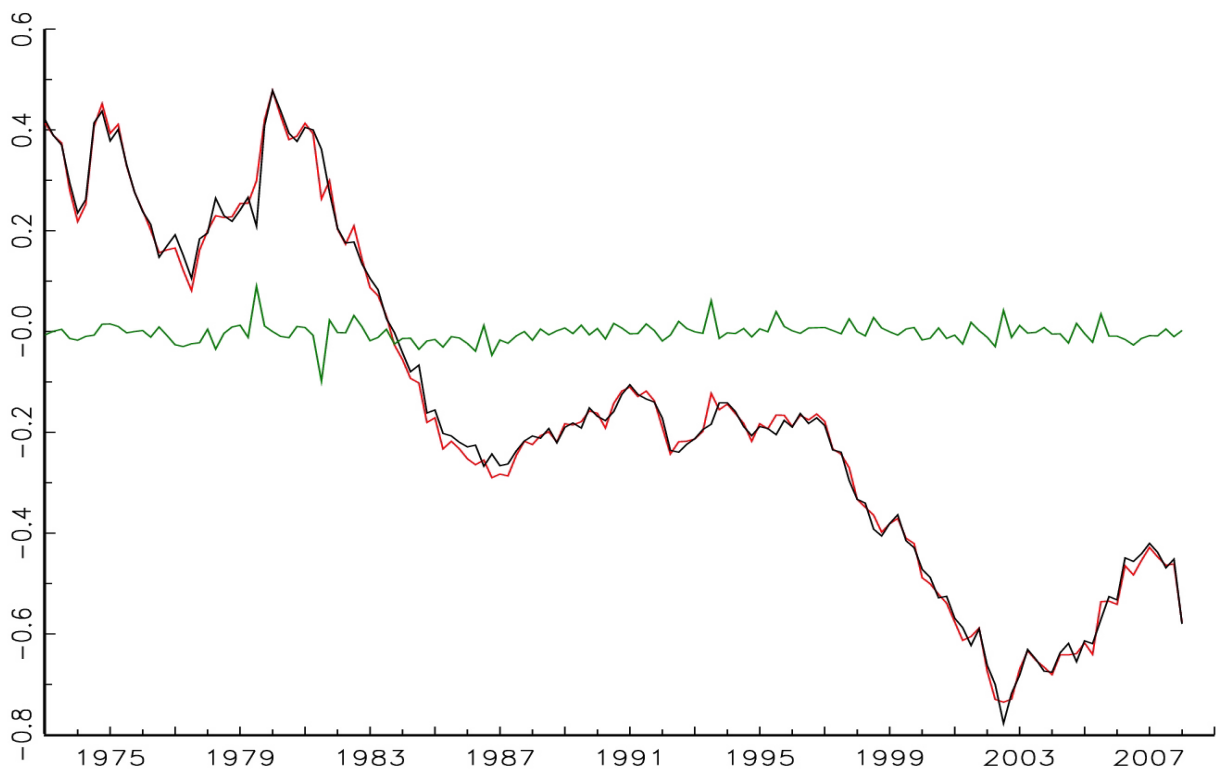

Figure 2: Approximation Accuracy, $n x a$ - red, predicted $n x a$ - black, $\xi$ - green.

from the approximation in (7). Our interest is not in the size of these individual errors, but in their combined effect on the accuracy of (8).

To address this issue we compared the actual value of $n x a_{t}$ computed from our data sample, against the implied value using the variables on the RHS of (8) and a value for $\rho$ of 0.993. (We discuss this choice for $\rho$ in Section 4.) Figure 2 plots the actual and implied values for $n x a_{t}$ over our sample period. We also plot the difference between the actual and implied values for $n x a_{t}: \xi_{t}=n x a_{t}-r_{t}^{\mathrm{NFA}}-\Delta n x_{t}-\frac{1}{\rho} n x a_{t-1}$. In addition to the approximation errors mentioned above, this error term also picks up the effects of measurement errors in the underlying data. Figure 2 clearly shows that there is very little difference between the actual and implied values for $n x a_{t}$. More precisely, the sample variance of the error term is 0.3 percent of the sample variance of the actual $n x a_{t}$ series. By this metric, the approximate dynamics for the U.S. external position in (8) are highly accurate.

\section{Modelling the U.S. External Position}

\subsection{The Present Value Equation}

We now use equation (8) to derive a simple present value equation for the U.S. external position. First we rewrite the equation as

$$
n x a_{t}=-\rho r_{t+1}^{\mathrm{NFA}}-\rho \Delta n x_{t+1}+\rho n x a_{t+1} .
$$

Recall that the linearization parameter, $\rho$, takes a value between zero and one. Next, we iterate forward and take expectations conditioned on period $-t$ information, $\Omega_{t}$, which includes the value of $n x a_{t}$. This produces

$$
n x a_{t}=-\sum_{i=1}^{\infty} \rho^{i} \mathbb{E}_{t}\left[r_{t+i}^{\mathrm{NFA}}+\Delta n x_{t+i}\right]+\lim _{i \rightarrow \infty} \mathbb{E}_{t} \rho^{i} n x a_{t+i}
$$


Notice that $\lim _{i \rightarrow \infty} \mathbb{E}_{t} \rho^{i} n x a_{t+i}<0$ if the U.S. is expected to simply issue more liabilities in the future to avoid defaulting on its existing international obligations. Similarly, $\lim _{i \rightarrow \infty} \mathbb{E}_{t} \rho^{i} n x a_{t+i}>0$ when U.S. trading partners are expected to run an analogous Ponzi scheme. We impose the no-Ponzi condition, $\lim _{i \rightarrow \infty} \mathbb{E}_{t} \rho^{i} n x a_{t+i}=0$ on the expression above to obtain

$$
n x a_{t}=-\sum_{i=1}^{\infty} \rho^{i} \mathbb{E}_{t}\left[r_{t+i}^{\mathrm{NFA}}+\Delta n x_{t+i}\right]
$$

Equation (10) relates the current U.S. external position to expectations concerning the future returns on foreign assets, foreign liabilities and the future growth in net exports. Importantly it embeds the central feature of the solvency constraint in (3). By definition, $n x a_{t}=n f a_{t}-\left(m_{t}-x_{t}\right)$, so there is a deterioration in the U.S. external position whenever there is a rise in the ratio of imports to exports that is not match by a rise in the ratio of foreign assets to liabilities. Equation (10) shows that this must be accompanied by expectations of: (i) higher future returns on foreign assets, (ii) lower future returns on foreign liabilities, and/or (iii) higher future growth in net exports.

Equation (10) is similar to the present value expression derived by G\&R, but it applies to the comprehensive measure of the external position, $n x a_{t}$, rather than its cyclical counterpart. It also clearly identifies two channels for international adjustment. Consider a case where $n x a_{t}$ is negative, because of either a net external debt position $\left(n f a_{t}<0\right)$ or a negative trade balance $\left(n x_{t}<0\right)$, or both. Suppose further that the expected future returns on foreign assets and liabilities are constant. Under these circumstances, (10) implies that all adjustment of the U.S. external position must come through expected growth in net exports, $\mathbb{E}_{t} \Delta n x_{t+i}>0$. This is the standard implication of the intertemporal approach to the current account, which G\&R call the "trade channel". When expected returns on foreign assets and liabilities are variable, external adjustment may also occur through the "valuation channel". As equation (10) shows, the U.S. may adjust to a negative $n x a_{t}$ position via higher expected future returns on foreign assets and/or lower expected returns on foreign liabilities, $\mathbb{E}_{t} r_{t+i}^{\mathrm{NFA}}>0$. In this case adjustment occurs via a predictable transfer of wealth from foreigners to domestic residents rather than through future trade flows.

We can also use equation (10) to think about the secular deterioration in the U.S. external position. By definition, the period-by-period changes in the external position comprises expected and unexpected components:

$$
\Delta n x a_{t+1}=\mathbb{E}_{t} \Delta n x a_{t+1}+\left(n x a_{t+1}-\mathbb{E}_{t} n x a_{t+1}\right) .
$$

Equation (10) implies that

$$
\begin{aligned}
\mathbb{E}_{t} \Delta n x a_{t+1} & =-\sum_{i=2}^{\infty} \rho^{i-1} \mathbb{E}_{t}\left[\Delta r_{t+i}^{\mathrm{NFA}}+\Delta n x_{t+i}-\Delta n x_{t+i-1}\right], \quad \text { and } \\
n x a_{t+1}-\mathbb{E}_{t} n x a_{t+1} & =-\sum_{i=2}^{\infty} \rho^{i-1}\left(\mathbb{E}_{t+1}-\mathbb{E}_{t}\right)\left[r_{t+i}^{\mathrm{NFA}}+\Delta n x_{t+i}\right]
\end{aligned}
$$


so the actual change in the external position is

$$
\begin{aligned}
\Delta n x a_{t+1}= & -\sum_{i=2}^{\infty} \rho^{i-1} \mathbb{E}_{t}\left[\Delta r_{t+i}^{\mathrm{NFA}}+\Delta n x_{t+i}-\Delta n x_{t+i-1}\right] \\
& -\sum_{i=2}^{\infty} \rho^{i-1}\left(\mathbb{E}_{t+1}-\mathbb{E}_{t}\right)\left[r_{t+i}^{\mathrm{NFA}}+\Delta n x_{t+i}\right] .
\end{aligned}
$$

Equation (12) identifies two sets of factors that could have contributed to the deterioration in the U.S. external position. The terms on the RHS in the first line show that deterioration could have been anticipated if: (i) the future returns on foreign asset portfolios were expected to rise relative to the returns on foreign liability portfolios, and/or (ii) the future growth in net exports was expected to accelerate. Alternatively, the terms in the second row show that the deterioration could reflect the effects of a series of shocks that lead to upward revisions in forecasts for future returns, $r_{t+i}^{\mathrm{NFA}}$, and export growth, $\Delta n x_{t+i}$.

Equation (12) provides more than just a perspective on the historical deterioration of the U.S. external position. It also supplies us with a tool to examine the expected future paths of external adjustment. For example, suppose that most of the historical deterioration in the U.S. position was attributable to good news about future returns and export growth via the second term on the RHS of equation (12). In this case, there is no change in the expected rate of external adjustment, $\mathbb{E}_{t} \Delta n x a_{t+i}$ for $i>0$ so the expected adjustment process following a fall in $n x a_{t}$ will have a longer duration. Alternatively, we may find that a good portion of the historical deterioration in the U.S. external position was due to greater optimism regarding future return differentials (i.e., a rise in $\mathbb{E}_{t} \Delta r_{t+i}^{\mathrm{NFA}}$ for $i>1$ ), and/or greater optimism concerning future net export growth (i.e., a rise in $\mathbb{E}_{t}\left[\Delta n x_{t+i}-\Delta n x_{t+i-1}\right]$ for $i>1$ ). In this case, $\mathbb{E}_{t} \Delta n x a_{t+i}$ rises for some $i>0$ so the expected adjustment process following a fall in $n x a_{t}$ could be much shorter if returns and net exports follow their expected paths.

In the next section we develop an empirical model that allows us to estimate the expectations concerning future returns and trade flows embedded in the U.S. external position over the last 35 years. We then use these estimates to study the factors contributing to the secular deterioration in the U.S. external position and the future adjustment paths consistent with these expectations.

\subsection{The Empirical Model}

We use the standard time-series methods developed by Campbell and Shiller (1987) to study the empirical predictions of (10). The key idea is to consider the implications of the present value model in (10) for a set of expectations conditioned on less information than was available to agents at the time.

Let $\Omega_{t}^{*}$ denote a subset of $\Omega_{t}$ that comprises the history of the U.S. external position, net export growth, the return differential and a vector of other variables, $w_{t}$, available to the researcher, i.e. $\Omega_{t}^{*}=$ $\left\{n x a_{t-i}, \Delta n x_{t-i}, r_{t-i}^{\mathrm{FA}}-r_{t-i}^{\mathrm{FL}}, w_{t-i}\right\}_{i \geq 0}$. By the law of iterated expectations, $\mathbb{E}\left[\mathbb{E}_{t} \Delta n x_{t+i} \mid \Omega_{t}^{*}\right]=\mathbb{E}\left[\Delta n x_{t+i} \mid \Omega_{t}^{*}\right]$ and $\mathbb{E}\left[\mathbb{E}_{t}\left(r_{t+i}^{\mathrm{NFA}}\right) \mid \Omega_{t}^{*}\right]=\mathbb{E}\left[r_{t+i}^{\mathrm{NFA}} \mid \Omega_{t}^{*}\right]$ for all $i>0$. Thus, taking expectations conditional on $\Omega_{t}^{*}$ on both sides of (10) produces

$$
\mathbb{E}\left[n x a_{t} \mid \Omega_{t}^{*}\right]=-\sum_{i=1}^{\infty} \rho^{i} \mathbb{E}\left[r_{t+i}^{\mathrm{NFA}}+\Delta n x_{t+i} \mid \Omega_{t}^{*}\right] .
$$

Because $n x a_{t}$ is an element in $\Omega_{t}^{*}$, the expectation on the left hand side is simply equal to $n x a_{t}$, so the 
expression above becomes

$$
n x a_{t}=-\sum_{i=1}^{\infty} \rho^{i} \mathbb{E}\left[r_{t+i}^{\mathrm{NFA}}+\Delta n x_{t+i} \mid \Omega_{t}^{*}\right]
$$

Unlike (10), this equation relates the U.S. external position to forecasts for future returns and net export growth that are conditioned on a subset of agents' information, $\Omega_{t}^{*} \subset \Omega_{t}$. It may seem strange that any additional information in $\Omega_{t}$ has no effect on $n x a_{t}$. Surely agents have information that is useful for forecasting future changes in returns that is not available to the researcher. However, $\Omega_{t}^{*}$ is not just any subset of agents' information. Because $\Omega_{t}^{*}$ contains current and past values of $n x a_{t}$ as well as the history of returns and the growth in net exports, it effectively contains all the information agents are using to calculate $\mathbb{E}_{t}\left[r_{t+i}^{\mathrm{NFA}}+\Delta n x_{t+i}\right]$ for $i>0$. For example, if agents have information that leads them to forecast higher growth in net exports twenty quarters head than they would based on their observations of $\left\{\Delta n x_{t-i}, r_{t-i}^{\mathrm{NFA}}\right\}_{i \geq 0}$, this information will be reflected in a lower value for $n x a_{t}$. An information set containing $\left\{n x a_{t-i}, \Delta n x_{t-i}, r_{t-i}^{\mathrm{NFA}}\right\}_{i \geq 0}$ will therefore capture this extra information affecting $\mathbb{E}_{t}\left[r_{t+i}^{\mathrm{NFA}}+\Delta n x_{t+i}\right]$. In short, we are using equation (14) to construct a particular subset of agents' information for which the implications of the present value model for the U.S. external position remain valid.

We can now use equation (14) to derive restrictions on the joint dynamics of the external position, net exports, and the return differential. For this purpose we must first compute $\mathbb{E}\left[r_{t+i}^{\mathrm{NFA}}+\Delta n x_{t+i} \mid \Omega_{t}^{*}\right]$ for $i>0$. Following Campbell and Shiller (1987), we assume that these forecasts can be calculated from a vector autoregression (VAR). Let the vector $z_{t}=\left[\begin{array}{llll}r_{t}^{\mathrm{NFA}} & \Delta n x_{t} & n x a_{t} & w_{t}\end{array}\right]^{\prime}$ follow a $k^{\prime}$ th. order VAR:

$$
z_{t}=a_{1} z_{t-1}+a_{2} z_{t-2}+\ldots . a_{k} z_{t-k}+u_{t}
$$

where $a_{i}$ are matrices of coefficients from each of the VAR equations, and $u_{t}$ is a vector of mean-zero shocks. To compute $\mathbb{E}\left[r_{t+i}^{\mathrm{NFA}}+\Delta n x_{t+i} \mid \Omega_{t}^{*}\right]$, the VAR is written in companion form:

$$
\left[\begin{array}{c}
z_{t} \\
\vdots \\
\vdots \\
z_{t-k+1}
\end{array}\right]=\left[\begin{array}{cccc}
a_{1} & \cdots & \cdots & a_{k} \\
I & & & \\
& \ddots & & \\
& & I & 0
\end{array}\right]\left[\begin{array}{c}
z_{t-1} \\
\vdots \\
\vdots \\
z_{t-k}
\end{array}\right]+\left[\begin{array}{c}
u_{t} \\
0 \\
\vdots \\
0
\end{array}\right]
$$

or, more compactly,

$$
Z_{t}=A Z_{t-1}+U_{t}
$$

Multi-period forecasts are easily computed from (16) as $\mathbb{E}\left[Z_{t+i} \mid Z_{t}\right]=A^{i} Z_{t}$, where $A^{i}$ denotes $i$ multiplications of the $A$ matrix.

Next, consider the implications of equation (14) for the dynamics of $Z_{t}$. Let the vectors

$$
\imath_{r}=\left[\begin{array}{lllll}
1 & 0 & 0 & \cdots & 0
\end{array}\right], \quad \imath_{n x}=\left[\begin{array}{lllll}
0 & 1 & 0 & \cdots & 0
\end{array}\right] \quad \text { and } \quad \imath_{n x a}=\left[\begin{array}{lllll}
0 & 0 & 1 & \cdots & 0
\end{array}\right]
$$

select $r_{t}^{\mathrm{NFA}}, \Delta n x_{t}$ and $n x a_{t}$ from $Z_{t}$. We can now compute the multi-period forecasts of net export growth and the return differential as $\mathbb{E}\left[r_{t+i}^{\mathrm{NFA}} \mid \Omega_{t}^{*}\right]=\imath_{r} A^{i} Z_{t}$ and $\mathbb{E}\left[\Delta n x_{t+i} \mid \Omega_{t}^{*}\right]=\imath_{n x} A^{i} Z_{t}$ for all $i>0$. Substituting 
these forecasts into (14) produces

$$
\begin{aligned}
\imath_{n x a} Z_{t}=n x a_{t} & =-\left(\imath_{r}+\imath_{n x}\right) \sum_{i=1}^{\infty} \rho^{i} A^{i} Z_{t} \\
& =-\left(\imath_{r}+\imath_{n x}\right) \rho A(I-\rho A)^{-1} Z_{t}
\end{aligned}
$$

This equation must hold for all possible values of the $Z_{t}$ vector $^{1}$, so the companion matrix $A$ from the VAR must satisfy

$$
\imath_{n x a}=-\left(\imath_{r}+\imath_{n x}\right) \rho A(I-\rho A)^{-1} .
$$

These restrictions can also be interpreted in terms of the specification errors plotted in Figure 2. These errors are defined as $\xi_{t+1}=n x a_{t+1}-r_{t+1}^{\mathrm{NFA}}-\Delta n x_{t+1}-\frac{1}{\rho} n x a_{t}$, so $\rho \mathbb{E}\left[\xi_{t+1} \mid \Omega_{t}^{*}\right]=-\left[\left(\imath_{r}+\imath_{n x}\right) \rho A+\imath_{n x a}(I-\rho A)\right] Z_{t}$. The restriction in (17) therefore implies that $\mathbb{E}\left[\xi_{t+1} \mid \Omega_{t}^{*}\right]=0$ for all values of $Z_{t}$.

Equation (17) contains a set of restrictions on the coefficients in the VAR system (15) that represent constraints on the joint dynamics of $r_{t}^{\mathrm{NFA}}, \Delta n x_{t}$, and $n x a_{t}$. They can be empirically examined for particular values of $\rho$ by computing a nonlinear Wald test from estimates of the $A$ matrix computed from OLS estimates of the VAR equations. This is really a test of a joint null hypothesis. In addition to the present value relation in (14) we are also testing the assumption that forecasts of future changes in fundamentals, $\mathbb{E}\left[r_{t+i}^{\mathrm{NFA}}+\right.$ $\left.\Delta n x_{t+i} \mid \Omega_{t}^{*}\right]$, can be computed from the VAR as $\left(\imath_{r}+\imath_{n x}\right) A^{i} Z_{t}$. This is not an innocuous assumption. Even if the dynamics of $z_{t}$ can be represented by a $k^{\prime}$ th. order VAR, these forecasts only represent the best forecasts of $r_{t+i}^{\mathrm{NFA}}+\Delta n x_{t+i}$ that can be computed using linear combinations of the variables in $Z_{t}$. It is possible that forecasts based on both linear and nonlinear combination of the variables in $Z_{t}$ have a lower mean squared forecast error. If this is the case, $\mathbb{E}\left[r_{t+i}^{\mathrm{NFA}}+\Delta n x_{t+i} \mid \Omega_{t}^{*}\right] \neq\left(\imath_{r}+\imath_{n x}\right) A^{i} Z_{t}$ and the restrictions in (17) will not hold true even if the present value relation in (14) is valid.

We can also use the VAR estimates to analyze the importance of the trade and valuation channels. Let $\hat{A}$ denote the estimated companion matrix from the VAR. We can write the predicted value for $n x a_{t}$ based on the VAR estimates as

$$
\begin{aligned}
\widehat{n x a}_{t} & =-\left(\imath_{r}+\imath_{n x}\right) \rho \hat{A}(I-\rho \hat{A})^{-1} Z_{t}, \\
& =-\imath_{r} \rho \hat{A}(I-\rho \hat{A})^{-1} Z_{t}-\imath_{n x} \rho \hat{A}(I-\rho \hat{A})^{-1} Z_{t}, \\
& =\widehat{n x a}_{t}^{\mathrm{V}}+\widehat{n x a}_{t}^{\mathrm{T}} .
\end{aligned}
$$

$\widehat{n x a}_{t}^{\mathrm{V}}$ and $\widehat{n x a}_{t}^{\mathrm{T}}$ are the predicted values for the valuation and trade components of the external position, given by

$$
n x a_{t}^{\mathrm{V}}=-\sum_{i=1}^{\infty} \rho^{i} \mathbb{E}\left[r_{t+i}^{\mathrm{NFA}} \mid \Omega_{t}^{*}\right] \quad \text { and } \quad n x a_{t}^{\mathrm{T}}=-\sum_{i=1}^{\infty} \rho^{i} \mathbb{E}\left[\Delta n x_{t+i} \mid \Omega_{t}^{*}\right] .
$$

We can use (18) to decompose the actual U.S. external position as

$$
\begin{aligned}
n x a_{t} & =\widehat{n x a}_{t}+\hat{\xi}_{t}, \\
& =\widehat{n x a}_{t}^{\mathrm{V}}+\widehat{n x a}_{t}^{\mathrm{T}}+\hat{\xi}_{t},
\end{aligned}
$$

\footnotetext{
${ }^{1}$ In deriving the equation we have implicity assumed that the eigenvalues of $\rho A$ are less than one in absolute value. Since $1>\rho>0$, this condition is satified if $z_{t}$ follows a convariance stationary time series process.
} 
where $\hat{\xi}_{t}$ represents the difference between the actual and predicted values for $n x a_{t}$ due to specification error. Clearly, $\hat{\xi}_{t}=0$ when the restrictions in (17) hold exactly.

Although Campbell and Shiller's methods have been used extensively to study present value models, a couple of points deserve emphasis here. First, researchers often compare the predicted and actual values for the variable determined by the present value relation (e.g. $n x a_{t}$ ) even when the restrictions in (17) are strongly rejected. These comparisons must be interpreted with care because the predicted values will be sensitive to the variables included in the VAR (i.e., the variables in the $w_{t}$ vector). If the present value relation in (10) does not hold, forecasts of $r_{t+i}^{\mathrm{NFA}}+\Delta n x_{t+i}$ based on $\Omega_{t}^{*} \subset \Omega_{t}$ will in general differ from agents' forecasts, and so can vary according to how we specify $\Omega_{t}^{*}$. Second, even in cases where the restrictions in (17) cannot be rejected, the predicted values for the valuation and trade components, $n x a_{t}^{\mathrm{V}}$ and $n x a_{t}^{\mathrm{T}}$, will be sensitive to the choice of variables included in the VAR. Because data on $n x a_{t}^{\mathrm{V}}$ and $n x a_{t}^{\mathrm{T}}$ is unavailable, we cannot use the history of $n x a_{t}^{\mathrm{V}}$ and $n x a_{t}^{\mathrm{T}}$ to capture information in agents' separate forecasts for the return differential and net export growth that was not contained in $\left\{n x a_{t-i}, \Delta n x_{t-i}, r_{t-i}^{\mathrm{FA}}-r_{t-i}^{\mathrm{FL}}, w_{t-i}\right\}_{i \geq 0}$. In other words, even when the history of $n x a_{t}$ is sufficient for capturing the private information in $\mathbb{E}_{t}\left[r_{t+i}^{\mathrm{NFA}}+\Delta n x_{t+i}\right]$, it may not be sufficient for $\mathbb{E}_{t}\left[r_{t+i}^{\mathrm{NFA}}\right]$ and $\mathbb{E}_{t}\left[\Delta n x_{t+i}\right]$. For this reason, our analysis of the valuation and trade components below will use alternative VAR specifications that include different variables in the $w_{t}$ vector.

\section{Results}

\subsection{Data}

Our analysis uses an extended version of the data set first constructed by Gourinchas and Rey (2007). They computed the market values for each U.S. foreign asset and liability category (e.g. equity, foreign direct investment, debt), by combining data on international positions with information on the capital gains and losses. We extend their data to 2008:III following the detailed procedures they describe in Gourinchas and Rey (2005). This provides us with time series on $F A_{t}, F L_{t}, R_{t}^{\mathrm{FA}}$ and $R_{t}^{\mathrm{FL}}$. We combine these series with data on U.S. exports and imports from the Bureau of Economic Analysis to construct $n x a_{t}, \Delta n x_{t}$ and $r_{t}^{\mathrm{NFA}}=r_{t}^{\mathrm{FA}}-r_{t}^{\mathrm{FL}}$. We also consider four additional variables in some of our VAR models. The growth in real U.S. GDP, $\Delta y_{t}$, the growth in the U.S. debt-to-GDP ratio, $\Delta d_{t}$; the spread between the yield on 10 year-U.S. government bonds and 3-month T-bills, $\nabla r_{t}$; and the quarterly real depreciation rate for the dollar against a trade-weighted index of foreign currencies, $\Delta \varepsilon_{t}$. A full description of our data is contained in the Appendix.

Table 1 presents summary statistics for the data we use in our analysis. Our sample runs for 1973:I to 2008:III and all variables are computed at a quarterly frequency. As one would expect, there is little serial correlation in net export growth, $\Delta n x_{t}$, or the log returns on assets and liabilities, $r_{t}^{\mathrm{FA}}$ and $r_{t}^{\mathrm{FL}}$. In contrast, the sample autocorrelations for our measure of the U.S. external position, $n x a_{t}$, decline rather slowly. We interpret these statistics to mean that $n x a_{t}$ follows a covariance stationary process with a good deal of persistence. Obviously, this interpretation relies on more than just the statistical evidence: the sample autocorrelations from a non-stationary $n x a_{t}$ process could look very similar to those we report in Table 2. Instead we take seriously the notion that the perceived likelihood of U.S. default was negligible over the past 35 years so that $\lim _{k \rightarrow \infty} \mathbb{E}_{t} n x a_{t+k}=0$ for all $t$ during our sample period. Clearly, agents' rational expectations could not satisfy this restriction unless the time series for $n x a_{t}$ was covariance stationary.

The lower panel of Table 1 reports sample statistics for the ancillary variables we use in our analysis: the 


\begin{tabular}{|c|c|c|c|c|c|c|}
\hline \multirow[t]{2}{*}{ Variable } & \multirow[t]{2}{*}{ Mean } & \multirow[t]{2}{*}{ Std. Dev. } & \multicolumn{4}{|c|}{ Autocorrelations at lags } \\
\hline & & & 1 & 4 & 8 & 12 \\
\hline$n x a_{t}$ & $-0 \cdot 147$ & $0 \cdot 331$ & 0.977 & $0 \cdot 904$ & $0 \cdot 807$ & $0 \cdot 672$ \\
\hline$\Delta n x_{t}$ & $-0 \cdot 002$ & $0 \cdot 032$ & $0 \cdot 169$ & $-0 \cdot 016$ & $-0 \cdot 014$ & $-0 \cdot 001$ \\
\hline$r_{t}^{\mathrm{NFA}}$ & $0 \cdot 000$ & $0 \cdot 024$ & $0 \cdot 156$ & $0 \cdot 084$ & $0 \cdot 065$ & $-0 \cdot 194$ \\
\hline$\Delta y_{t}$ & 0.007 & $0 \cdot 008$ & $0 \cdot 289$ & $0 \cdot 048$ & $-0 \cdot 194$ & $-0 \cdot 246$ \\
\hline$\Delta \varepsilon_{t}$ & $0 \cdot 001$ & $0 \cdot 027$ & $0 \cdot 078$ & $0 \cdot 163$ & $0 \cdot 089$ & $0 \cdot 064$ \\
\hline$\Delta d_{t}$ & $0 \cdot 004$ & $0 \cdot 011$ & $0 \cdot 875$ & 0.516 & $0 \cdot 195$ & $0 \cdot 163$ \\
\hline$\nabla r_{t}$ & $0 \cdot 398$ & $0 \cdot 326$ & $0 \cdot 870$ & $0 \cdot 419$ & $0 \cdot 010$ & $-0 \cdot 323$ \\
\hline
\end{tabular}

Notes: Sample statistics for the U.S. external position, $n x a_{t}$; the growth in "net exports" (i.e., the ratio of exports to imports), $\Delta n x_{t}$; the return differential between the log return on U.S. foreign assets and foreign liabilities, $r_{t}^{\mathrm{NFA}}$; the growth in U.S. GDP, $\Delta y_{t}$; the real dollar depreciation rate, $\Delta \varepsilon_{t}$, the growth in the U.S. government debt-to-GDP ratio, $\Delta d_{t}$, the spread between the yield on 10-year U.S. government bonds and 3-mointh T-bills, $\nabla r_{t}$; the exports-to-liability ratio, $X_{t} / R_{t}^{\mathrm{FL}} F L_{t-1}$; the imports-to-asset ratio, $M_{t} / R_{t}^{\mathrm{FA}} F A_{t-1}$, and the asset-to-liability ratio, $N F A_{t}$. All series are sampled at the quarterly frequency and span 1973:I to 2008:III.

growth in GDP, $\Delta y_{t}$; the real depreciation rate for the dollar, $\Delta \varepsilon_{t}$; the growth in the debt-to-GDP ratio, $\Delta d_{t}$; and the yield spread, $\nabla r_{t}$. The latter two series display some persistence, but all appear covariance stationary.

Table 2 compares the behavior of returns in our data set with the returns computed in two recent studies. Curcuru, Dvorak, and Warnock (2008) argue that the returns on U.S. foreign asset and liability portfolios used in earlier studies were biased upward. They compute portfolio returns using two different data sources: monthly equity and bond portfolios from Bertaut and Tryon (2007) and data from the Bureau of Economic Analysis (BEA). Columns (i) and (ii) compare their data on annualized returns at a monthly frequency with returns in our data, while columns (iii) and (iv) compare returns at a quarterly frequency. As the table shows, there is little evidence of similar upward bias in our data. We also compared our returns with the ones computed by Forbes (2009). She finds that the average total return on U.S. foreign assets (liabilities) for the period 2002-2006 was $11.2 \%$ (4.3\%), producing a return differential of $6.9 \%$. Our returns show that for the same period the return on U.S. foreign assets (liabilities) was $11.05 \%$ (4.10\%), giving a return differential of $6.94 \%$. These comparisons show that our results concerning the valuation channel are not attributable to differences between our data on returns and the series used in other studies.

The results of Granger Causality tests for the variables in our VARs are presented in Table 3. Column (i) - (iii) report $\chi^{2}$ statistics and associated asymptotic p-values for the null that the coefficients on the variable listed at the head of each column equal zero. These statistics are computed from a regression of the dependent variable shown in the left hand column on lags of the variables listed at the head of columns (i) - (iii). Columns (iv) - (vii) report analogous $\chi^{2}$ statistics for the variable listed in at the head of each column in a regression that also include lags $n x a_{t}, r_{t}^{\mathrm{NFA}}$ and $\Delta n x_{t}$. The first two rows in each panel report 
Table 2: Comparison of Returns

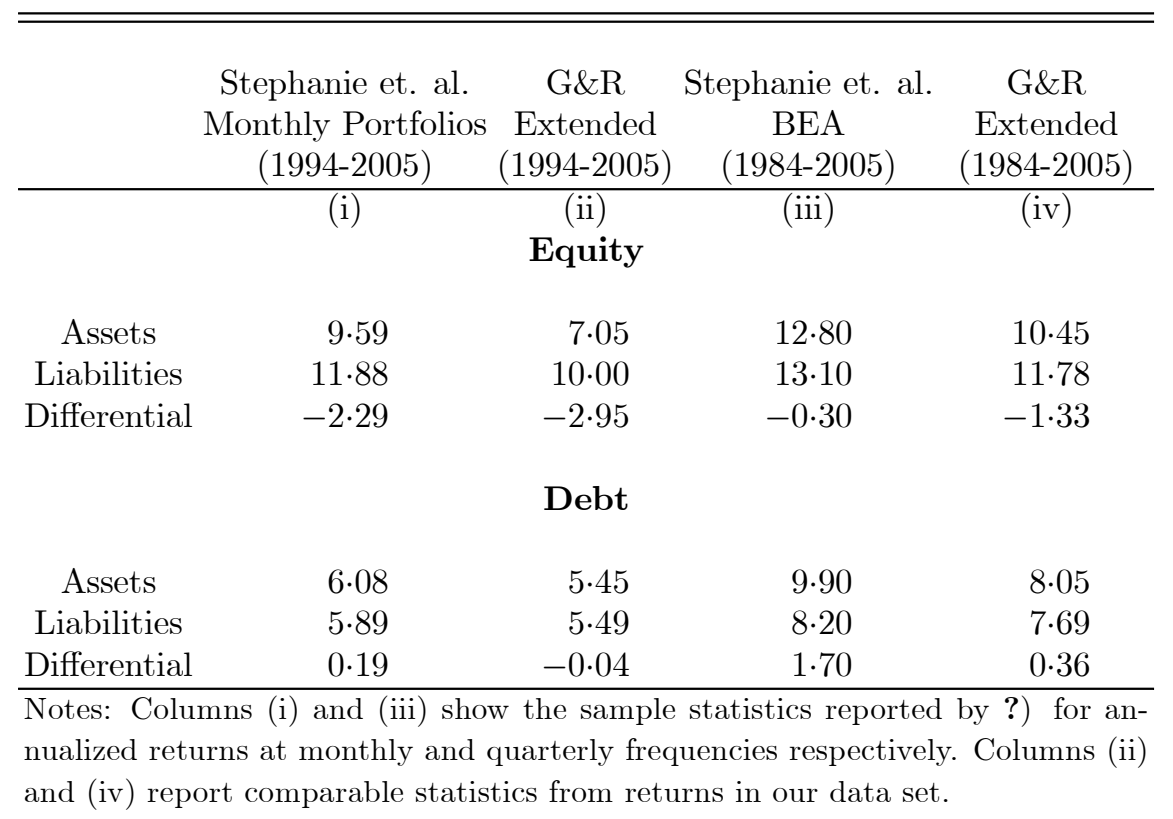

tests on the coefficients in the equations for the return differential, $r_{t}^{\mathrm{NFA}}$, and net export growth, $\Delta n x_{t}$. The third row presents $\chi^{2}$ statistics for the null that the sum of the coefficients for each dependent variable from the $r_{t}^{\mathrm{NFA}}$ and $\Delta n x_{t}$ equations equals zero. This is equivalent to testing for the joint statistical significance of the coefficients on the forecasting variables in an equation with $r_{t}^{\mathrm{NFA}}+\Delta n x_{t}$ as the dependent variable.

There are two noteworthy features of the table: First, none of the statistics in column (i) are statistically significant. Consequently, we cannot reject the hypothesis that current and lagged values of $n x a_{t}$ have no incremental forecasting power for future values of $r_{t}^{\mathrm{NFA}}, \Delta n x_{t}$ and $r_{t}^{\mathrm{NFA}}+\Delta n x_{t}$ beyond that contained in the history of $r_{t}^{N F A}$ and $\Delta n x_{t}$. This result is not inconsistent with the present value model. The U.S. external position should only have incremental forecasting power for $r_{t}^{\mathrm{NFA}}+\Delta n x_{t}$ when agents' forecasts are more precise than those based on the history of $r_{t}^{N F A}$ and $\Delta n x_{t}$ alone. The second feature concerns the forecasting power of GDP growth, $\Delta y_{t}$. The statistics in column (iv) show that the lagged values of $\Delta y_{t}$ have incremental forecasting power for future returns and net export growth individually. Again, this finding is not inconsistent with the present value model (see above), but it does mean that estimates of the Trade and Valuation components may not be robust to the exclusion of GDP growth from the VAR. GDP growth also has incremental forecasting power for $r_{t}^{\mathrm{NFA}}+\Delta n x_{t}$. This should not be the case if there are sufficient lags of $n x a_{t}, r_{t}^{\mathrm{NFA}}$ and $\Delta n x_{t}$ in the forecasting equations and the present value model holds true. To ensure that our results are robust, below we report results derived from VARs for $z_{t}=\left[\begin{array}{lll}r_{t}^{\mathrm{NFA}} & \Delta n x_{t} & n x a_{t}\end{array}\right]^{\prime}$ and $z_{t}=\left[\begin{array}{llll}r_{t}^{\mathrm{NFA}} & \Delta n x_{t} & n x a_{t} & \Delta y_{t}\end{array}\right]^{\prime}$. 
Table 3: Grange Causality Tests

\begin{tabular}{|c|c|c|c|c|c|c|c|}
\hline \multirow{2}{*}{$\begin{array}{l}\text { Forecast } \\
\text { Variable } \\
\end{array}$} & \multicolumn{7}{|c|}{ Forecasting Variables } \\
\hline & $n x a_{t-i}$ & $r_{t-i}^{\mathrm{NFA}}$ & $\Delta n x_{t-i}$ & $\Delta y_{t-i}$ & $\Delta \varepsilon_{t-i}$ & $\nabla r_{t-i}$ & $\Delta d_{t-i}$ \\
\hline & (i) & (ii) & (iii) & (iv) & $(\mathrm{v})$ & (vi) & (vii) \\
\hline $\begin{array}{l}\text { A: } 1 \text { lag } \\
r_{t}^{\text {NFA }}\end{array}$ & $\begin{array}{c}2 \cdot 419 \\
(0 \cdot 120)\end{array}$ & $\begin{array}{c}4.948 \\
(0 \cdot 026)\end{array}$ & $\begin{array}{c}0 \cdot 009 \\
(0 \cdot 924)\end{array}$ & $\begin{array}{c}4 \cdot 120 \\
(0 \cdot 042)\end{array}$ & $\begin{array}{c}0.590 \\
(0 \cdot 443)\end{array}$ & $\begin{array}{c}0 \cdot 044 \\
(0 \cdot 834)\end{array}$ & $\begin{aligned}> & 0.001 \\
& (0.996)\end{aligned}$ \\
\hline$\Delta n x_{t}$ & $\begin{array}{c}0.523 \\
(0 \cdot 470)\end{array}$ & $\begin{array}{c}1.788 \\
(0 \cdot 181)\end{array}$ & $\begin{array}{c}3 \cdot 259 \\
(0 \cdot 071)\end{array}$ & $\begin{array}{c}13.534 \\
(>0.001)\end{array}$ & $\begin{array}{c}3 \cdot 385 \\
(0 \cdot 066)\end{array}$ & $\begin{array}{c}4 \cdot 516 \\
(0 \cdot 034)\end{array}$ & $\begin{array}{c}1 \cdot 772 \\
(0 \cdot 183)\end{array}$ \\
\hline$r_{t}^{\mathrm{NFA}}+\Delta n x_{t}$ & $\begin{array}{c}2 \cdot 293 \\
(0 \cdot 130)\end{array}$ & $\begin{array}{c}6 \cdot 291 \\
(0 \cdot 012)\end{array}$ & $\begin{array}{c}2 \cdot 691 \\
(0 \cdot 101)\end{array}$ & $\begin{array}{c}4 \cdot 409 \\
(0 \cdot 036)\end{array}$ & $\begin{array}{c}1 \cdot 436 \\
(0 \cdot 231)\end{array}$ & $\begin{array}{c}3 \cdot 089 \\
(0 \cdot 079)\end{array}$ & $\begin{array}{c}1 \cdot 241 \\
(0 \cdot 265)\end{array}$ \\
\hline $\begin{array}{l}\text { B: } 2 \text { lags } \\
r_{t}^{\text {NFA }}\end{array}$ & $\begin{array}{c}4 \cdot 483 \\
(0 \cdot 106)\end{array}$ & $\begin{array}{c}5 \cdot 194 \\
(0 \cdot 074)\end{array}$ & $\begin{array}{c}1.526 \\
(0 \cdot 466)\end{array}$ & $\begin{array}{c}3 \cdot 729 \\
(0 \cdot 155)\end{array}$ & $\begin{array}{c}5.932 \\
(0 \cdot 052)\end{array}$ & $\begin{array}{c}0 \cdot 812 \\
(0 \cdot 666)\end{array}$ & $\begin{array}{c}0 \cdot 802 \\
(0 \cdot 670)\end{array}$ \\
\hline$\Delta n x_{t}$ & $\begin{array}{c}0 \cdot 698 \\
(0 \cdot 706)\end{array}$ & $\begin{array}{c}2 \cdot 043 \\
(0 \cdot 360)\end{array}$ & $\begin{array}{c}1.813 \\
(0.404)\end{array}$ & $\begin{array}{c}18.280 \\
(>0.001)\end{array}$ & $\begin{array}{c}3 \cdot 303 \\
(0 \cdot 192)\end{array}$ & $\begin{array}{c}6 \cdot 723 \\
(0 \cdot 035)\end{array}$ & $\begin{array}{c}3 \cdot 773 \\
(0 \cdot 152)\end{array}$ \\
\hline$r_{t}^{\mathrm{NFA}}+\Delta n x_{t}$ & $\begin{array}{c}2 \cdot 077 \\
(0 \cdot 354)\end{array}$ & $\begin{array}{c}5 \cdot 560 \\
(0 \cdot 062)\end{array}$ & $\begin{array}{c}0 \cdot 685 \\
(0 \cdot 710)\end{array}$ & $\begin{array}{c}7 \cdot 268 \\
(0 \cdot 026)\end{array}$ & $\begin{array}{c}1 \cdot 852 \\
(0 \cdot 396)\end{array}$ & $\begin{array}{c}3.759 \\
(0 \cdot 153)\end{array}$ & $\begin{array}{c}3 \cdot 643 \\
(0 \cdot 162)\end{array}$ \\
\hline
\end{tabular}

Notes: The table reports $\chi^{2}$ statistics and associated asymptotic p-values for the null that the coefficients on the variable listed at the head of each column equal zero. For the tests in columns (i) - (iii), the lagged values of $n x a_{t-i}, r_{t-i}^{\mathrm{NFA}}$ and $\Delta n x_{t-i}$ are included in the forecasting regression. For the tests in columns (iv) - (iii) the lagged values of $n x a_{t-i}$, $r_{t-i}^{\mathrm{NFA}}, \Delta n x_{t-i}$ and the variable listed at the head of each column are included. The variable being forecast are reported in the left hand columns. The results in Panel A use 1 lag of the forecasting variables, those in panel B use 2 lags.

\section{Drivers of the U.S. External Position}

We begin our analysis by studying how different factors contributed to the historical deterioration of the U.S. external position. For this purpose we first estimated VARs for $\left\{r_{t}^{\mathrm{NFA}}, \Delta n x_{t}, n x a_{t}\right\}$, called Model A; and for $\left\{r_{t}^{\mathrm{NFA}}, \Delta n x_{t}, n x a_{t}, \Delta y_{t}\right\}$, called Model B. We focus on the implications of 1'st. and 2'nd. order VARs, but results from higher orders are similar. For each estimated model, we chose the value for $\rho \in(0,1)$ that minimizes the sample variance of the specification errors, $\hat{\xi}_{t}$, in equation (20). These values are reported in the first row of Table 4. When they were used to test the restrictions on the VAR coefficients in (17), we found that none of the (nonlinear) Wald statistics were statistically significant. Of course precise inference in this situation is tricky. The standard practice following Campbell and Shiller (1987) is to conduct the Wald test using a pre-specified value for $\rho$. Our procedure of choosing $\rho$ means that the Wald statistic we compute will be lower than those using other values for $\rho$. This does not mean that the restrictions in (17) are automatically satisfied because the minimized variance of the specification error may still be positive. 
However, it does mean that the true asymptotic distribution of Wald statistic under the null with $\rho \in(0,1)$ differs from the standard chi-squared. To account for this we used a boostrap procedure (described in the Appendix) to approximate the true p-values of our test statistics. These p-values are reported in the second row of Table 4. They indicate that the restrictions on the VAR coefficients cannot be rejected as standard significance levels for any of our specifications.

Table 4: Variance Decomposition of $n x a$

\begin{tabular}{|c|c|c|c|c|}
\hline \multirow[b]{2}{*}{ Estimates } & \multicolumn{2}{|c|}{ Model A } & \multicolumn{2}{|c|}{ Model B } \\
\hline & $\operatorname{VAR}(1)$ & $\operatorname{VAR}(2)$ & $\operatorname{VAR}(1)$ & $\operatorname{VAR}(2)$ \\
\hline$\rho$ & $\begin{array}{c}0.993 \\
(0 \cdot 090)\end{array}$ & $\begin{array}{c}0.993 \\
(0 \cdot 200)\end{array}$ & $\begin{array}{c}0 \cdot 993 \\
(0 \cdot 175)\end{array}$ & $\begin{array}{c}0 \cdot 993 \\
(0 \cdot 360)\end{array}$ \\
\hline$\beta_{\mathrm{v}}$ & $\begin{array}{c}0 \cdot 540 \\
(0 \cdot 002)\end{array}$ & $\begin{array}{c}0.553 \\
(0 \cdot 002)\end{array}$ & $\begin{array}{c}0.523 \\
(0 \cdot 004)\end{array}$ & $\begin{array}{c}0.518 \\
(0 \cdot 046)\end{array}$ \\
\hline$\beta_{\mathrm{T}}$ & $\begin{array}{c}0 \cdot 460 \\
(0 \cdot 001)\end{array}$ & $\begin{array}{c}0 \cdot 447 \\
(0 \cdot 001)\end{array}$ & $\begin{array}{c}0 \cdot 477 \\
(0 \cdot 003)\end{array}$ & $\begin{array}{c}0 \cdot 482 \\
(0 \cdot 003)\end{array}$ \\
\hline$A I C$ & $-9 \cdot 572$ & $-9 \cdot 484$ & $-23 \cdot 036$ & $-22 \cdot 589$ \\
\hline $\begin{array}{l}\text { Notes: Th } \\
\text { VARs, deno } \\
\left\{r_{t}^{\text {NFA }}, \Delta n x\right. \\
\text { minimizes t } \\
\text { the nonline } \\
\text { in parenthe } \\
\text { with asymp } \\
\text { information } \\
\text { table. }\end{array}$ & $\begin{array}{l}\text { table repo } \\
\text { ed by VAR } \\
n x a_{t}, \Delta y_{t} \\
\text { e sample va } \\
\text { Wald test } \\
\text { s. The mid } \\
\text { otic standa } \\
\text { riterion for }\end{array}$ & $\begin{array}{l}\text { results fro } \\
\text { and VAR }(2 \\
\text { r Model B. } \\
\text { nce of the s } \\
\text { the restrict } \\
\text { rows report } \\
\text { errors show } \\
\text { ch VAR spe }\end{array}$ & $\begin{array}{l}\text { 1'st. and } \\
\left.x_{t}, n x a_{t}\right\} \text { in } \\
\text { ports the va } \\
\text { rs. Bootstra } \\
\text { eported bel } \\
\text { lope coeffici } \\
\text { The valu } \\
\text { rted in the }\end{array}$ & $\begin{array}{l}\text { nd. order } \\
\text { odel A, and } \\
\text { for } \rho \text { that } \\
\text { p-values for } \\
\text { each value } \\
\text { s from }(21) \\
\text { or Akaike's } \\
\text { trow of the }\end{array}$ \\
\hline
\end{tabular}

We cannot reject the hypothesis that our measure of the U.S. external position embeds a set of expectations concerning future returns and net exports for a particular value of $\rho \in(0,1)$. We note, however, that these values for $\rho$ are higher than the sample means of $1-\mathfrak{X}_{t} / R_{t}^{\mathrm{FL}} F L_{t-1}$ and $1-\mathfrak{M}_{t} / R_{t}^{\mathrm{FA}} F A_{t-1}$. This difference does not impair the accuracy of our approximation. Figure 2 showed the accuracy of (8) with $\rho=0.993$. What is does mean is that variations in the U.S. external position over the past 35 years appear to have been heavily influenced by revisions in expectations about returns and net export far into the future. As we shall see, it is the variations in these long-horizon expectations that are important in identifying the future expected path of external adjustment.

The lower rows of the Table 4 report the estimates of the variance decomposition for $n x a_{t}$ over the sample period. Equation (20) implies that:

$$
\mathbb{V}\left(n x a_{t}\right)=\mathbb{C V}\left(\widehat{n x a}_{t}^{\mathrm{V}}, n x a_{t}\right)+\mathbb{C V}\left(\widehat{n x a}_{t}^{\mathrm{T}}, n x a_{t}\right)+\mathbb{C V}\left(\hat{\xi}_{t}, n x a_{t}\right)
$$

where $\mathbb{V}($.$) and \mathbb{C V}(.,$.$) denote the variance and covariance operators, respectively. The first term on the$ RHS identifies the contribution of variations in the estimated valuation component, $\widehat{n x a}_{t}^{\mathrm{V}}$, to the variance 
of $n x a_{t}$. The second term identifies the variance contribution of the estimates trade component, $\widehat{n x a}_{t}^{\mathrm{T}}{ }^{2}$ To estimate these variance contributions, we compute the slope coefficient from the OLS regression of the estimated component on $n x a_{t}$ :

$$
\widehat{n x a}_{t}^{\mathrm{V}}=\beta_{\mathrm{v}} n x a_{t}+\zeta_{t}^{\mathrm{V}} \quad \text { and } \quad \widehat{n x a}_{t}^{\mathrm{T}}=\beta_{\mathrm{T}} n x a_{t}+\zeta_{t}^{\mathrm{T}} .
$$

By least squares, $\beta_{\mathrm{V}}=\mathbb{C V}\left(\widehat{n x a}_{t}^{\mathrm{V}}, n x a_{t}\right) / \mathbb{V}\left(n x a_{t}\right)$ and $\beta_{\mathrm{T}}=\mathbb{C V}\left(\widehat{n x a}_{t}^{\mathrm{T}}, n x a_{t}\right) / \mathbb{V}\left(n x a_{t}\right)$ so the regression coefficient provide estimates of the variance contributions. We also computed heteroskedastic consistent standard errors for these estimates with the White (1980) procedure.

As Table 4 shows, our estimates of the variance contributions are very similar for models based on the 1st and 2nd order VAR specifications. The estimates from Model A imply that variations in the estimated valuation component account for 54 percent of the variance in $n x a_{t}$, while variations in the trade component account for the remaining 46 percent. When the components are estimated from Model B, the split is very similar: 52 percent is attributable to the valuation component and 48 percent to trade component. Although GDP growth has statistically significant forecasting power for future returns and trade flows, the similarity between these variance decompositions shows that our results are economically robust to different VAR specifications. The last row in Table 4 reports the value of Akaike's information criterion for each model specification. Based on this measure, we will focus on the implications of the 1'st-order VARs in our analysis below.

Figure 3 provides complimentary visual evidence on these decompositions based on our estimates of Model B. Here we plot the $n x a_{t}$, together with the estimated trade and valuation components, $n x a_{t}^{\mathrm{T}}$ and $n x a_{t}^{\mathrm{V}}$. (The plot for $n x a_{t}$ almost exactly coincides with the plot of $n x a_{t}^{\mathrm{T}}+n x a_{t}^{\mathrm{V}}$, so the estimated specification errors are economically insignificant.) The figure shows how the estimated trade and valuation components contributed to the secular deterioration of the U.S. external position over the past 35 years. In particular, it is clear that both components contributed equally to the large falls in $n x a_{t}$ in the early 1980s and late 1990s. More generally, quarter-by-quarter changes in the valuation and trade components are strongly correlated.

We now examine the factors driving change in the U.S. external position. Our aim here is to investigate the extent to which changes in $n x a_{t}$ over the past 35 years contain expectations about future trade flows and returns that will bring the U.S. external position back into balance.

Our first task is to decompose the changes in $n x a_{t}$ into expected and unexpected components. The VAR implies that the $k$-quarter change can be decomposed as

$$
\Delta^{k} n x a_{t+k}=\widehat{\mathbb{E}}_{t} \Delta^{k} n x a_{t+k}+\left(n x a_{t+k}-\widehat{\mathbb{E}}_{t} n x a_{t+k}\right)
$$

where

$$
\widehat{\mathbb{E}}_{t} \Delta^{k} n x a_{t+k}=\imath_{n x a}\left(\hat{A}^{k}-I\right) Z_{t}, \quad \text { and } \quad n x a_{t+k}-\widehat{\mathbb{E}}_{t} n x a_{t+k}=\imath_{n x a} \sum_{i=0}^{k-1} \hat{A}^{i} \hat{U}_{t+k-i} .
$$

Here $\hat{U}_{t}$ denotes the companion form for the VAR residuals. We compute the variance contribution of the

\footnotetext{
${ }^{2}$ The p-values for the Wald statistics in Table 4 imply that we cannot reject the null that $\mathbb{C V}\left(\hat{\xi}_{t}, n x a_{t}\right)=0$ at standard significance levels.
} 


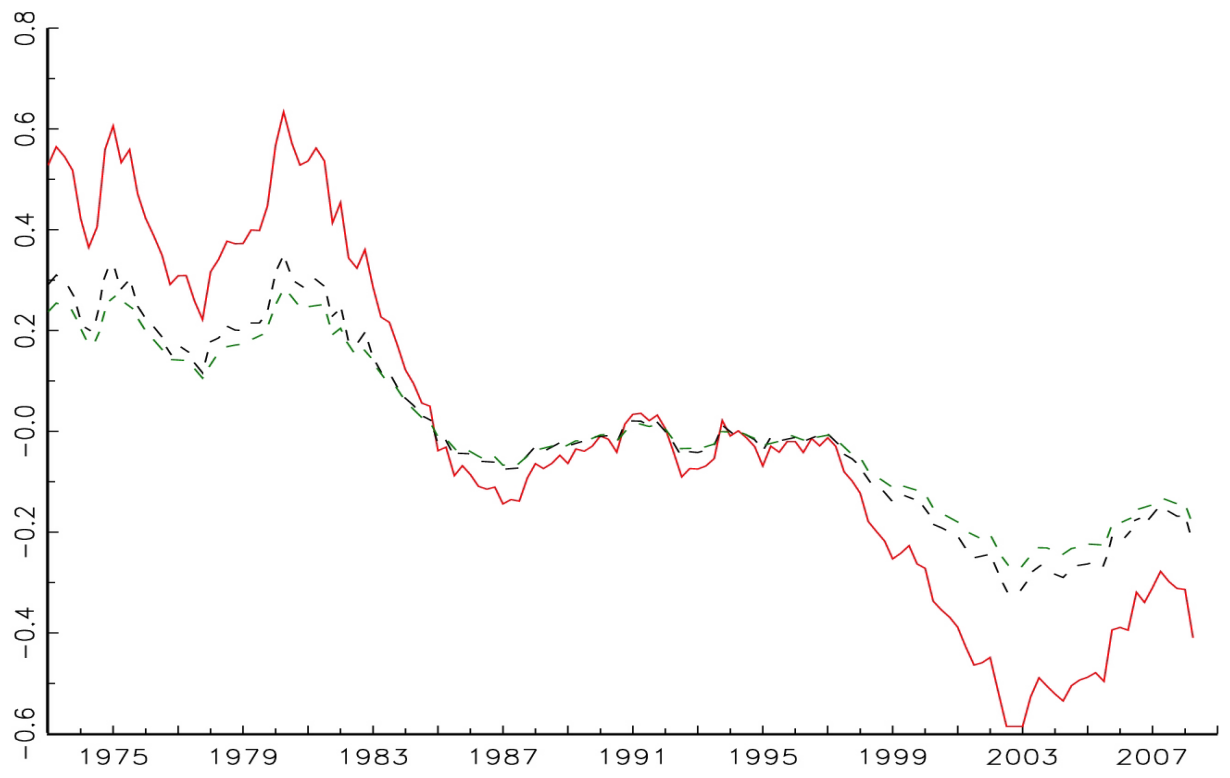

Figure 3: Historical Decomposition of the U.S. External Position $n x a-$ red, $n x a^{\mathrm{V}}-$ dashed black, $n x a^{\mathrm{T}}-$ dashed green

expected and unexpected components as the slope coefficients from

$$
\widehat{\mathbb{E}}_{t} \Delta^{k} n x a_{t+k}=\beta_{\mathrm{E}}^{k} \Delta^{k} n x a_{t+k}+\zeta_{t+k}^{\mathrm{E}} \quad \text { and } \quad\left(n x a_{t+k}-\widehat{\mathbb{E}}_{t} n x a_{t+k}\right)=\beta_{\mathrm{U}}^{k} n x a_{t+k}+\zeta_{t+k}^{\mathrm{U}} .
$$

The regression coefficient $\beta_{\mathrm{E}}^{k}$ provides an estimate of the variance contribution of expected changes in $n x a_{t}$ at the $k$-quarter horizon, while the $\beta_{\mathrm{U}}^{k}$ coefficient estimates the variance contribution of unexpected changes. Under the null that all changes in $n x a_{t}$ are unpredictable, $\beta_{\mathrm{E}}^{k}=0, \beta_{\mathrm{U}}^{k}=1$ and the error terms follow an $\mathrm{MA}(k-1)$ process. We compute standard errors for our estimates of $\beta_{\mathrm{E}}^{k}$ and $\beta_{\mathrm{U}}^{k}$ under this null using the Newey and West (1987) procedure.

Figure 4 plots the estimates of $\beta_{\mathrm{E}}^{k}$ and $\beta_{\mathrm{U}}^{k}$ against horizons ranging from 1 to 60 quarters (15 years) using our estimates of Model B. (Estimates based on Model A are essential identical.) We also plot a 95 percent confidence band associated with these estimates derived from the Newey-West standard errors. As the figure shows, unexpected variations in $n x a_{t}$ are the dominant source of variation in $\Delta^{k} n x a_{t+k}$ over short horizons; they account for 95 percent at the one quarter horizon. This decomposition slowly changes as the horizon lengthens. By ten years, the variance contribution of unexpected changes has fallen to approximately 75 percent, and by 15 years it is roughly 66 percent. This fall is mirrored, of course, by the rising variance contribution of expected changes in $n x a_{t}$. This is an important finding. Since we cannot reject the solvency restrictions imposed on the VAR, the estimated variations in $\mathbb{E}_{t} \Delta^{k} n x a_{t+k}$ embed agents' period- $t$ expectations about how the U.S. will meet its international obligations.

We can gain a fuller understanding of the findings in Figures 3 and 4 by studying the implications of the present value model for $\mathbb{E}_{t} \Delta^{k} n x a_{t+k}$ - the expected rate of external adjustment. In particular, equation 


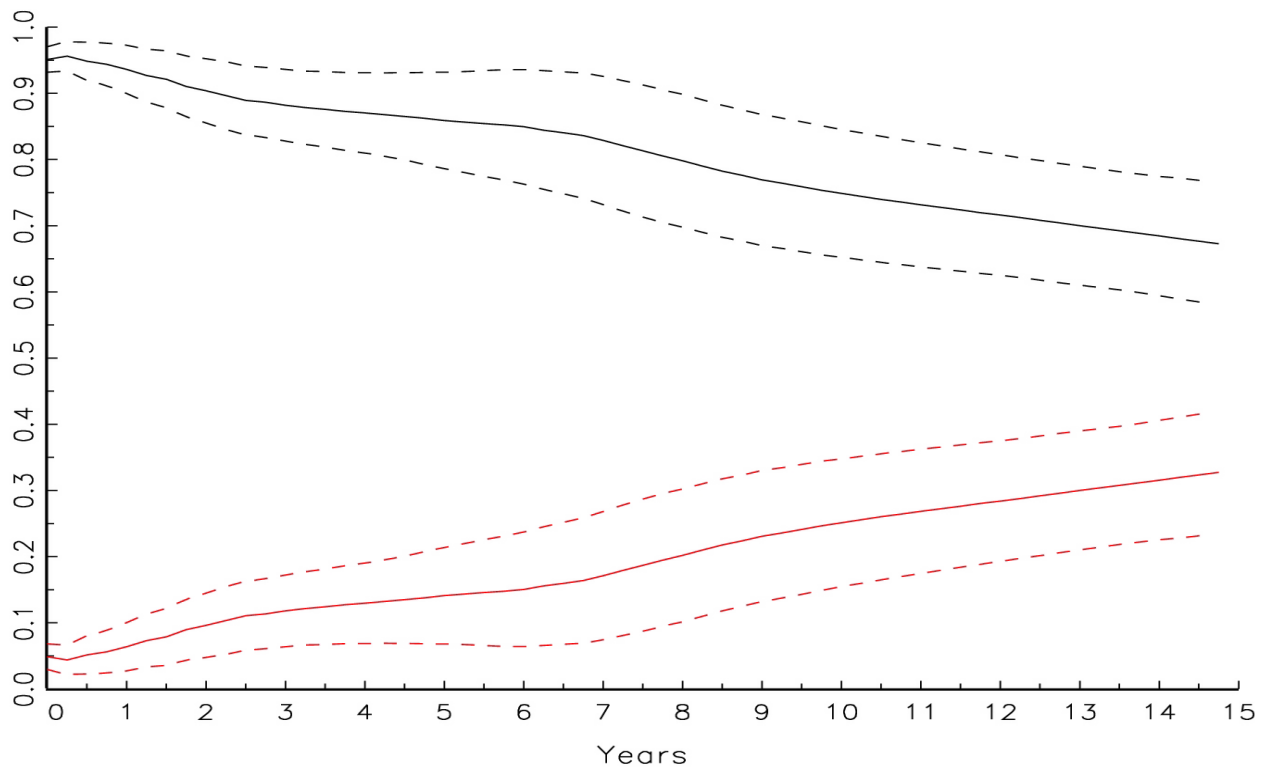

Figure 4: Decomposition of $\mathbb{V}\left(\Delta^{h} n x a_{t+h}\right)$ by horizon $k$ in years $\mathbb{V}\left(\mathbb{E}_{t} \Delta^{k} n x a_{t+k}\right)$ contribution - red, $\mathbb{V}\left(n x a_{t+k}-\mathbb{E}_{t} n x a_{t+k}\right)$ contribution - black

(10) implies that

$$
\mathbb{E}_{t} \Delta^{k} n x a_{t+k}=\sum_{i=1}^{k} \rho^{i} \mathbb{E}_{t}\left[r_{t+i}^{\mathrm{NFA}}+\Delta n x_{t+i}\right]-\left(1-\rho^{k}\right) \sum_{i=k+1}^{\infty} \rho^{i-k} \mathbb{E}_{t}\left[r_{t+i}^{\mathrm{NFA}}+\Delta n x_{t+i}\right]
$$

Expectations concerning future return differentials and net export growth affect the expect adjustment path via two channels. First, long-horizons expectations beyond $k$ determine the expected future level of the external position, $\mathbb{E}_{t} n x a_{t+k}$, through the solvency conditions embedded in the present value equation (10). Higher expectations concerning $r_{t+i}^{\mathrm{NFA}}$ and/or $\Delta n x_{t+i}$ lower $\mathbb{E}_{t} n x a_{t+k}$ and hence reduce the expected rate of future adjustment, $\mathbb{E}_{t} \Delta^{k} n x a_{t+k}$, via the second term on the RHS of (24). Notice that this effect will be smaller for any set of expectations and horizon $k$ the larger the value of the discount factor $\rho$. Short-horizon expectations concerning the return differential and net export growth affect the expected rate of adjustment through the second channel. In this case higher expectations for $r_{t+i}^{\mathrm{NFA}}$ and/or $\Delta n x_{t+i}$ with horizons $i \leq k$ raise the expect rate of adjustment via the first term on the RHS of (24) because agents anticipate a near-term improvement in net exports and/or the U.S. net foreign asset position.

The present value model also implies that

$$
\Delta^{k} n x a_{t+k}-\mathbb{E}_{t} \Delta^{k} n x a_{t+k}=-\sum_{i=1}^{\infty} \rho^{i}\left(\mathbb{E}_{t+k}-\mathbb{E}_{t}\right)\left[r_{t+k+i}^{\mathrm{NFA}}+\Delta n x_{t+k+i}\right]
$$

so unexpected adjustments to the external position reflect news concerning return differentials and net export growth at horizons beyond $k$. By definition, $\Delta^{k} n x a_{t+k}=\Delta^{k} n f a_{t+k}+\Delta^{k} n x_{t+k}$, where $n f a_{t}$ is the $\log$ ratio of the value of U.S. foreign assets to foreign liabilities at the start of period $t$. Unexpected changes in $\Delta^{k} n x a_{t+k}$ therefore capture the unanticipated capital gains and losses on existing foreign assets and liabilities (i.e., the unexpected variations in $\left.\Delta^{k} n f a_{t+k}\right)$ and unanticipated changes in trade flows (i.e., the unexpected 
variations in $\left.\Delta^{k} n x_{t+k}\right)$. Our VAR estimates imply that unexpected variations in trade flows contribute less to the variance of the unexpected adjustments in the external position as the horizon $k$ rises. In particular, the estimates from Model B imply that the contribution falls from 63 to 22 percent as $k$ rises from 1 to 50. These estimates imply that unanticipated capital gains and loss on existing foreign assets and liabilities contribute significantly to the unexpected variations in the U.S. external position at all horizons over the past 35 years.

Equations (24) and (25) facilitate interpretation of the plots in Figure 4. Specifically, suppose that most of the variation in agents' expectations concerning future return differentials and net export growth are at medium to long horizons (e.g. more than three years). Because the value for $\rho$ in our model is close to unity, (25) implies that variations in these expectations contribute significantly to the volatility of $\Delta^{k} n x a_{t+k}-\mathbb{E}_{t} \Delta^{k} n x a_{t+k}$ at all horizons $k$. In contrast, equation (24) implies that there will be little variation in $\mathbb{E}_{t} \Delta^{k} n x a_{t+k}$ at short horizons $k$ because the $1-\rho^{k}$ is close to zero. Variations in the longhorizon forecasts for returns and net export growth will therefore have little influence on $\mathbb{E}_{t} \Delta^{k} n x a_{t+k}$ until $k$ becomes large. These predictions for the volatility of $\mathbb{E}_{t} \Delta^{k} n x a_{t+k}$ and $\Delta^{k} n x a_{t+k}-\mathbb{E}_{t} \Delta^{k} n x a_{t+k}$ are consistent with the variance contributions plotted in Figure 4. When changes in the U.S. external position are primarily associated with variations in long-horizon expectations for returns and net export growth, short-term variations in $n x a_{t}$ will be largely unpredictable, but long-term changes will reflect agents' prior expectations about how the U.S. will meet its international obligations.

\section{Future Adjustment}

We now use our model to study the likely course of adjustment in the U.S. external position. First we examine the adjustment paths implied by the trade and valuation channels. In the former, we focus on the implications of expectations concerning the future course of net exports; in the latter we study the implications of expected future returns. We then consider the likely role of exchange rate variations in these adjustment processes. In particular, we examine the extent to which the anticipated path of adjustment embeds expectations of a depreciating dollar.

\subsection{Adjustment via the Trade and Valuation Channels}

We identify agent's expectations about future external adjustment via the trade and valuation channels by rewriting (24) as:

$$
\mathbb{E}_{t} \Delta^{k} n x a_{t+k}=\mathbb{E}_{t} \Delta^{k} n x a_{t+k}^{\mathrm{T}}+\mathbb{E}_{t} \Delta^{k} n x a_{t+k}^{\mathrm{V}}
$$

where

$$
\begin{aligned}
& \mathbb{E}_{t} \Delta^{k} n x a_{t+k}^{\mathrm{T}}=\sum_{i=1}^{k} \rho^{i} \mathbb{E}_{t} \Delta n x_{t+i}-\left(1-\rho^{k}\right) \sum_{i=k+1}^{\infty} \rho^{i-k} \mathbb{E}_{t} \Delta n x_{t+i} \quad \text { and } \\
& \mathbb{E}_{t} \Delta^{k} n x a_{t+k}^{\mathrm{V}}=\sum_{i=1}^{k} \rho^{i} \mathbb{E}_{t} r_{t+i}^{\mathrm{NFA}}-\left(1-\rho^{k}\right) \sum_{i=k+1}^{\infty} \rho^{i-k} \mathbb{E}_{t} r_{t+i}^{\mathrm{NFA}}
\end{aligned}
$$

$\mathbb{E}_{t} \Delta^{k} n x a_{t+k}^{\mathrm{T}}$ identifies anticipated adjustment via the trade channel insofar as it reflects expectations of future net export growth. Analogously, expected future changes in the return differential, $r_{t+i}^{\mathrm{NFA}}=r_{t+i}^{\mathrm{FA}}-r_{t+i}^{\mathrm{FL}}$ 
drive anticipated adjustment via the valuation channel, $\mathbb{E}_{t} \Delta^{k} n x a_{t+k}^{\mathrm{V}}$. To assess the relative importance of these channels, we first use our model estimates to compute a variance decomposition for $\mathbb{E}_{t} \Delta^{k} n x a_{t+k}$ over the past 35 years. For this purpose we estimate the slope coefficients from

$$
\widehat{\mathbb{E}}_{t} \Delta^{k} n x a_{t+k}^{\mathrm{V}}=\gamma_{\mathrm{v}}^{k} \widehat{\mathbb{E}}_{t} \Delta^{k} n x a_{t+k}+\varsigma_{t}^{\mathrm{V}} \quad \text { and } \quad \widehat{\mathbb{E}}_{t} \Delta^{k} n x a_{t+k}^{\mathrm{T}}=\gamma_{\mathrm{T}}^{k} \widehat{\mathbb{E}}_{t} \Delta^{k} n x a_{t+k}+\varsigma_{t}^{\mathrm{T}}
$$

The rationale for these regressions is analogous to that behind (23). Here $\gamma_{\mathrm{T}}^{k}$ and $\gamma_{\mathrm{V}}^{k}$ identify the variance contribution of the trade and valuation channels to anticipated future adjustment. The dependent variables are constructed from (26) using estimates of Model B to calculate the terms on the RHS. $\widehat{\mathbb{E}}_{t} \Delta^{k} n x a_{t+k}$ is computed from (22) with the estimates of Model B.

Figure 5 plots the estimates of $\gamma_{\mathrm{T}}^{k}$ and $\gamma_{\mathrm{v}}^{k}$ against horizons $k$ ranging from 1 to 20 quarters (5 years), together with 95 percent confidence bands. These bands account for the presence of serial correlation in the regression errors and sampling variation in $\widehat{\mathbb{E}}_{t} \Delta^{k} n x a_{t+k}{ }^{3}$ As the figure shows, variations in expected trade flows dominate expected returns at horizons of less than a year. Beyond that, expected changes in the returns on foreign assets and liabilities account for roughly half the variation in $\mathbb{E}_{t} \Delta^{k} n x a_{t+k}$, with the remaining half due to changing expectations concerning net export growth. These results indicate that most near-term adjustment of the U.S. external position is expected to come via the trade channel, but over longer horizons adjustment is expected to come via changing returns and the growth in net exports.

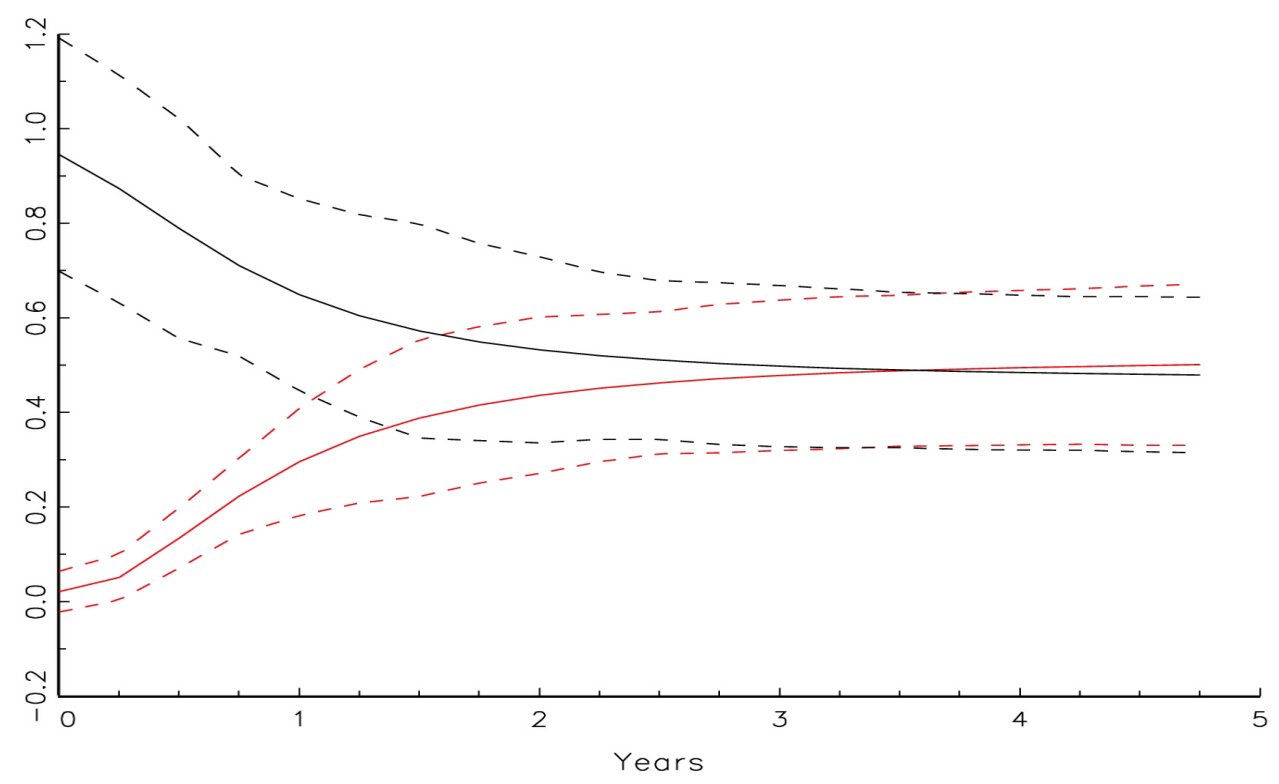

Figure 5: Decomposition of $\mathbb{V}\left(\mathbb{E}_{t} \Delta^{h} n x a_{t+h}\right)$ by horizon $k$ in years $\mathbb{V}\left(\mathbb{E}_{t} \Delta^{k} n x a_{t+k}^{\mathrm{V}}\right)$ contribution - red, $\mathbb{V}\left(\mathbb{E}_{t} \Delta^{k} n x a_{t+k}^{\mathrm{T}}\right)$ contribution - black

The plots in Figure 5 also reflect the volatility of expectations at different horizons. In particular, the declining variance contribution of $\widehat{\mathbb{E}}_{t} \Delta^{k} n x a_{t+k}^{\mathrm{T}}$ indicates that near-term expectations concerning future net

\footnotetext{
${ }^{3}$ Because we estimate $\mathbb{E}_{t} \Delta^{k} n x a_{t+k}$, we need to account for sampling variation when computing the standard errors of the coefficient estimates. For this purpose we use an IV procedure akin to 2 SLS: We replaced $\widehat{\mathbb{E}}_{t} \Delta^{k} n x a_{t+k}$ by $\Delta^{k} n x a_{t+k}$ on the RHS and then used $\widehat{\mathbb{E}}_{t} \Delta^{k} n x a_{t+k}$ as an instrument for $\Delta^{k} n x a_{t+k}$. The coefficient estimates are identical to OLS. Their standard errors are computed from the IV procedure with the Newey and West (1987) covariance estimator that allows for the presence of heteroskedasticity and an $M A(k-1)$ error process.
} 
export growth are more volatile than long-term expectations. Conversely, the rising variance contribution of $\widehat{\mathbb{E}}_{t} \Delta^{k} n x a_{t+k}^{\mathrm{V}}$ reflects the fact that expectations concerning returns at long horizons are more volatile than those at short horizons.

We next used the model estimates to compute the anticipated future adjustment path from any initial point. Figure 6 plots this adjustment path using the U.S. external position in 2008:III (the end of our data sample) as the initial external position. Specifically, the red line plots $\widehat{\mathbb{E}}_{T} n x a_{T+k}=\widehat{\mathbb{E}}_{T} \Delta^{k} n x a_{T+k}+$ $n x a_{T}$ against $k$ where $n x a_{T}$ is the external position in 2008:III, and $\widehat{\mathbb{E}}_{T} \Delta^{k} n x a_{T+k}$ is an estimate of the anticipated adjustment path given expectations about future returns and net export growth in 2008:III. For the purpose of comparison, Figure 6 also plots the paths for $\widehat{\mathbb{E}}_{T} n x a_{T+k}^{\mathrm{T}}=\widehat{\mathbb{E}}_{T} \Delta^{k} n x a_{T+k}^{\mathrm{T}}+n x a_{T}$ in blue and $\widehat{\mathbb{E}}_{T} n x a_{T+k}^{\mathrm{V}}=\widehat{\mathbb{E}}_{T} \Delta^{k} n x a_{T+k}^{\mathrm{V}}+n x a_{T}$ in green. These plots estimate the adjustment path for $n x a_{t}$ if either $\mathbb{E}_{t} r_{t+i}^{\mathrm{NFA}}$ or $\mathbb{E}_{t} \Delta n x_{t+i}$ are constant for all $i>0 .{ }^{4}$ In other words, they show how the U.S. external balance would be expected to adjust if there is no change in the future return differential, or no change in future net exports. Of course, neither path is dynamically consistent with the value of $n x a_{T}$, because it embeds expectations of changing future returns and net export growth. Comparing $\widehat{\mathbb{E}}_{T} n x a_{T+k}$ with $\widehat{\mathbb{E}}_{T} n x a_{T+k}^{\mathrm{T}}$ and $\widehat{\mathbb{E}}_{T} n x a_{T+k}^{\mathrm{v}}$ is useful nevertheless, because differences between the plots quantifies the contribution of expected future variations in returns and net export growth.

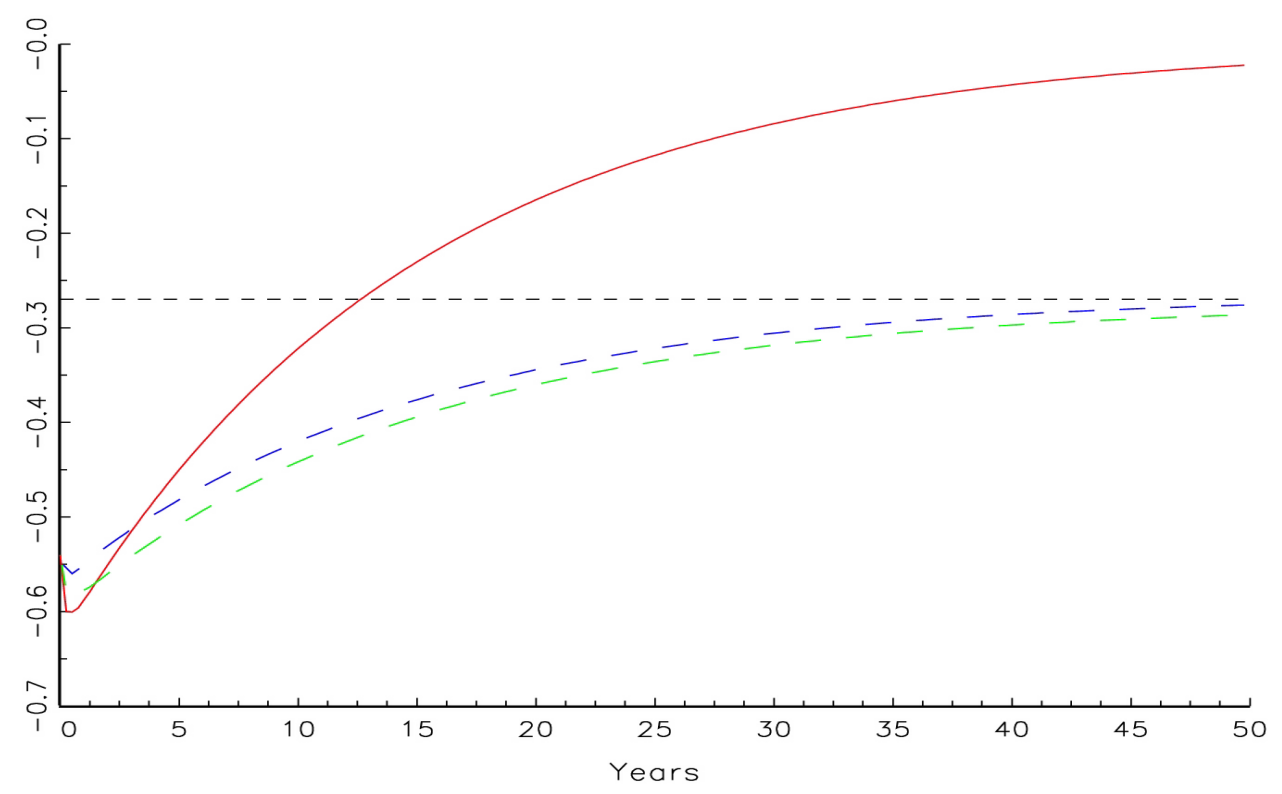

Figure 6: Future Adjustment Paths: $\widehat{\mathbb{E}}_{T} n x a_{T+k}$ - solid red, $\widehat{\mathbb{E}}_{T} n x a_{T+k}^{\mathrm{T}}-$ dashed blue, $\widehat{\mathbb{E}}_{T} n x a_{T+k}^{\mathrm{V}},-$ dashed green

Three features stand out from Figure 6: First, the expected adjustment process has a very long duration. We estimate the half-life to be 52 quarters, or 13 years. (This is the point where the red plot intersects the dashed black line.) This is the time it would take for $n x a_{t}$ to rise 50 percent of the way towards external balance $\left(n x a_{t}=0\right)$ if there were no further shocks that pushed future returns and net exports away from their expected paths. The second feature in Figure 6 concerns the growing difference between the estimated

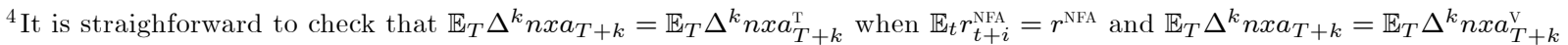
when $\mathbb{E}_{t} \Delta n x_{t+i}=\Delta n x$ for all $i>0$.
} 
adjustment path, $\widehat{\mathbb{E}}_{T} n x a_{T+k}$, and the plots for $\widehat{\mathbb{E}}_{T} n x a_{T+k}^{\mathrm{T}}$ and $\widehat{\mathbb{E}}_{T} n x a_{T+k}^{\mathrm{V}}$ as $k$ increases. This tells us that the expected future changes in both returns and net exports embedded in $n x a_{T}$ have a significant impact on the anticipated adjustment path beyond the first few quarters. In fact, as we increase the horizon further the paths for $\widehat{\mathbb{E}}_{T} n x a_{T+k}^{\mathrm{T}}$ and $\widehat{\mathbb{E}}_{T} n x a_{T+k}^{\mathrm{V}}$ both flatten out well below zero. This means that expected adjustment via the trade and valuation channels alone are insufficient to bring the U.S. external position back into balance. Figure 6 also shows that the expected adjustment path begins with a short-term deterioration of the U.S. external position: i.e., $\widehat{\mathbb{E}}_{T} n x a_{T+k}$ falls below $n x a_{T}$ for $5>k>0$. This delay arises because long-term expectations of higher net export growth and return differentials dominate the effect of near-term expectations on $\mathbb{E}_{T} \Delta^{k} n x a_{T+k}^{\mathrm{T}}$ and $\mathbb{E}_{T} \Delta^{k} n x a_{T+k}^{\mathrm{V}}$ for $k<5$.

\subsection{Future Adjustment and the Dollar}

The expectations concerning net exports and the return differential driving the anticipated adjustment path for the U.S. external position do not rest upon explicit assumptions concerning the future behavior of the U.S. dollar. Because behavior of the dollar is only one of the many potential factors driving future net export growth and the return differential, the adjustment path in Figure 6 could be consistent with several expected future paths for the dollar exchange rate. We now use our model to estimate these expectations.

Variations in the international value of the dollar can affect the U.S. external position via both the trade and valuation channels. In the case of the trade channel, the reasoning is straightforward. Our model estimates show that by 2008 agents were expecting the U.S. to honor its international obligations via steady future growth in net exports. Under the reasonable assumption that the Marshall-Lerner condition holds for most of these expected future trade flows, the expected growth in net exports should be associated with a future real depreciation of the dollar against the currencies of the U.S. main trading partners. Of course, future variations in the dollar could also be correlated with the other factors affecting trade flows, such as GDP growth; so, a priori, it is hard to determine the degree of expected real depreciation consistent with external adjustment via the trade channel. Instead we examine the extent to which variations in expected future net export growth have been correlated with expected real depreciation of the dollar.

Let $\mathcal{E}_{t}$ denote the real U.S. dollar exchange rate defined as the relative price of the trade-weighted basket of foreign consumption goods in terms of U.S. consumption goods. A real depreciation in the dollar is therefore represented by a rise in $\mathcal{E}_{t}$. To evaluate the degree of real depreciation associated with adjustment via the trade channel we estimate

$$
\frac{1}{k} \Delta^{k} \varepsilon_{t+k}=a_{0}^{\mathrm{T}}+a_{1}^{\mathrm{T}} \widehat{n x a}_{t}^{\mathrm{T}}+\nu_{t+k}^{\mathrm{T}}
$$

where $\varepsilon_{t}=\ln \mathcal{E}_{t}$, for different horizons $k=\{1,4\}$. The reasoning above suggests that the estimates of $a_{1}$ should be negative. However, our prime interest is in the size of the estimates at different horizons. As above, we allow for serial correlation in the residuals, $\nu_{t+k}$, when $k>1$, and sampling variability in $\widehat{n x a}_{t}^{\mathrm{T}}$ when computing the standard errors associated with $a_{1}^{\mathrm{T}}$.

The role of the dollar in the valuation channel is more complex. Recall, that valuation effects are present when there is an expected difference between the future log real returns on U.S. foreign assets and liabilities, $r_{t}^{\mathrm{FA}}$ and $r_{t}^{\mathrm{FL}}$. It is important to recognize that these returns are portfolio returns, not the returns on individual assets. $r_{t}^{\mathrm{FA}}$ varies because the returns on the individual foreign assets held by U.S. agents change, or because 
the composition of the foreign asset held change, or both. Similarly, variations in $r_{t}^{\mathrm{FL}}$ may reflect changes in the returns on individual U.S. assets held by foreign agents, and/or changes in the composition of foreign agents' portfolios of U.S. assets. Thus, expectations for $r_{t+i}^{\mathrm{NFA}}=r_{t+i}^{\mathrm{FA}}-r_{t+i}^{\mathrm{FL}}$ are a complex combination of forecasts concerning the future returns on individual assets and the composition of the portfolios.

The composition of the asset and liability portfolios affects how the return differential, $r_{t+i}^{\mathrm{NFA}}$, varies with dollar depreciation rates. To illustrate this point, let $\lambda_{j, t}^{\mathrm{FA}}$ and $\lambda_{j, t}^{\mathrm{FL}}$ denote the shares of U.S. foreign assets and liabilities denominated in foreign currency $j$ in period $t$. Following (Campbell and Viceira (2002)), we can approximate the return differential, $r_{t+1}^{\mathrm{NFA}} \equiv r_{t+1}^{\mathrm{FA}}-r_{t+1}^{\mathrm{FL}}$ as

$$
\begin{aligned}
r_{t+1}^{\mathrm{NFA}}= & \sum_{j} \lambda_{j, t}^{\mathrm{FA}}\left(\hat{\mathfrak{r}}_{j, t+1}^{\mathrm{FA}}+\Delta \varepsilon_{j, t+1}\right)+\left(1-\sum_{j} \lambda_{j, t}^{\mathrm{FA}}\right) \mathfrak{r}_{t+1}^{\mathrm{FA}}+\Omega_{t}^{\mathrm{FA}} \\
& -\sum_{j} \lambda_{j, t}^{\mathrm{FL}}\left(\hat{\mathfrak{r}}_{j, t+1}^{\mathrm{FL}}+\Delta \varepsilon_{j, t+1}\right)-\left(1-\sum_{j} \lambda_{j, t}^{\mathrm{FL}}\right) \mathfrak{r}_{t+1}^{\mathrm{FL}}-\Omega_{t}^{\mathrm{FL}},
\end{aligned}
$$

where; $\mathfrak{r}_{t+1}^{\mathrm{FA}}$ and $\mathfrak{r}_{t+1}^{\mathrm{FL}}\left(\hat{\mathfrak{r}}_{j, t+1}^{\mathrm{FA}}\right.$ and $\left.\hat{\mathfrak{r}}_{j, t+1}^{\mathrm{FL}}\right)$ denote log returns measured relative to U.S. (country $j$ ) consumption, and $\Delta \varepsilon_{j, t+1}$ is the real depreciation rate between the dollar and currency $j$, all between $t$ and $t+1$. The $\Omega_{t}^{\mathrm{FA}}$ and $\Omega_{t}^{\mathrm{FL}}$ terms are present because we are approximating the difference between the log portfolio returns, $r_{t+1}^{\mathrm{FA}}$ and $r_{t+1}^{\mathrm{FL}}$, which are nonlinear functions of $\log$ returns and the shares. ${ }^{5}$ Now suppose that all U.S. foreign liabilities are denominated in dollars and all U.S. foreign assets are denominated in foreign currencies. In this case $\sum_{j} \lambda_{j, t}^{\mathrm{FA}}=1$ and $\lambda_{j, t}^{\mathrm{FL}}=0$ for all $j$, so (29) becomes

$$
r_{t+1}^{\mathrm{NFA}}=\sum_{j} \lambda_{j, t}^{\mathrm{FA}}\left(\hat{\mathfrak{r}}_{j, t+1}^{\mathrm{FA}}+\Delta \varepsilon_{j, t+1}\right)-\mathfrak{r}_{t+1}^{\mathrm{FL}}+\Omega_{t}^{\mathrm{FA}}-\Omega_{t}^{\mathrm{FL}} .
$$

Ceteris paribus, a real depreciation of the dollar increases the return differential because it raises the return on foreign assets measured in terms of U.S. consumption. Alternatively, if all U.S. foreign assets and liabilities are denominated in foreign currencies (i.e., $\sum_{j} \lambda_{j, t}^{\mathrm{FA}}=\sum_{j} \lambda_{j, t}^{\mathrm{FL}}=1$ ), (29) simplifies to

$$
r_{t+1}^{\mathrm{NFA}}=\sum_{j}\left(\lambda_{j, t}^{\mathrm{FA}}-\lambda_{j, t}^{\mathrm{FL}}\right) \Delta \varepsilon_{j, t+1}+\sum_{j}\left(\lambda_{j, t}^{\mathrm{FA}} \hat{\mathrm{r}}_{j, t+1}^{\mathrm{FA}}-\lambda_{j, t}^{\mathrm{FL}} \hat{\mathfrak{r}}_{j, t+1}^{\mathrm{FL}}\right)+\Omega_{t}^{\mathrm{FA}}-\Omega_{t}^{\mathrm{FL}}
$$

In this case the (direct) effect of a dollar depreciation verses currency $j$ depends on the difference in the relative exposure $\lambda_{j, t}^{\mathrm{FA}}-\lambda_{j, t}^{\mathrm{FL}}$. Of course, in both cases the total affect on the return differential also depends on the correlation between the real depreciation rate and returns $\left(\mathfrak{r}_{t+1}^{\mathrm{FA}}, \hat{\mathfrak{r}}_{j, t+1}^{\mathrm{FA}}, \mathfrak{r}_{t+1}^{\mathrm{FL}}\right.$ and $\left.\hat{\mathfrak{r}}_{j, t+1}^{\mathrm{FL}}\right)$. These indirect effects can either dampen or magnify the direct effects of a dollar depreciation. For example, suppose a real dollar depreciation was accompanied by an immediate rise in U.S. long-term real interest rates. Insofar as U.S. long-term bonds comprise some part of U.S. external liabilities, $\mathfrak{r}_{t+1}^{\mathrm{FL}}$ will fall when long-term bond prices rise, so the direct and indirect effects on $r_{t+1}^{\mathrm{NFA}}$ in (30) work in the same direction.

There are two important points to take away from this discussion: First, there is no strong theoretical prior that expected future return differentials have either a positive or negative correlation with expected future depreciation of the dollar. Indeed, the correlation could be time-varying as the composition of the asset and liability portfolios change. Historically, roughly 70 percent of U.S. foreign liabilities have been in dollars, but there is no reason why this need continue in the future. Second, expected future return

\footnotetext{
${ }^{5}$ A detailed derivation of (29) is provided in the appendix.
} 
differentials could be strongly correlated with the expected future depreciation of the dollar against one foreign currency, but not another. As equation (31) shows, the relative exposure term, $\lambda_{j, t}^{\mathrm{FA}}-\lambda_{j, t}^{\mathrm{FL}}$, could be very different across different foreign currencies $j$. Consequently, while the depreciation of the dollar against the currency of a major trading partner could facilitate adjustment via the trade channel, the depreciation may have little beneficial impact via the valuation channel.

We examine the correlation between expected real dollar depreciation rates and expected return differentials by estimating

$$
\frac{1}{k} \Delta^{k} \varepsilon_{j, t+k}=a_{0}^{\mathrm{V}}+a_{1}^{\mathrm{V}} \widehat{n x a_{t}^{\mathrm{V}}}+\nu_{t+k}^{\mathrm{V}}
$$

for different horizons $k=\{1,4\}$, and foreign currencies $j$. Recall that $\widehat{n x a}_{t}^{\mathrm{V}}$ is our VAR estimate of the valuation component: $n x a_{t}^{\mathrm{V}}=-\sum_{i=1}^{\infty} \rho^{i} \mathbb{E}\left[r_{t+i}^{\mathrm{NFA}} \mid \Omega_{t}^{*}\right]$, so the regression coefficient $b_{1}$ will be negative if the expected future depreciation rate is positively correlated with the present value of future return differentials. As above, we allow for serial correlation in the residuals, $\eta_{t+k}$, when $k>1$, and sampling variability in $\widehat{n x a}_{t}^{\mathrm{V}}$ when computing the standard errors associated with $a_{1}^{\mathrm{V}}$.

For comparison purposes, we also compute the OLS estimates of

$$
\frac{1}{k} \Delta^{k} \varepsilon_{j, t+k}=a_{0}+a_{1} n x a_{t}+\nu_{t+k}
$$

and estimates of (28) -(33) with the return differential, $\frac{1}{k} \sum_{i=1}^{k} r_{t+1}^{\mathrm{NFA}}$, replacing the deprecation rate.

Table 5 reports the estimates of regressions (28) -(33) using the depreciation rate for the dollar against a trade-weighted basket of currencies, the Deutchemark/Euro, the British Pound, and the Japanese Yen. The upper rows show that both the trade and valuation components have forecasting power for the future real depreciation of the U.S. dollar against the currencies of its major trading partners. In addition, the negative estimates of $a_{1}^{\mathrm{T}}$ and $a_{1}^{\mathrm{V}}$ indicate that expected depreciation is positively correlated with expectations of higher net export growth and higher return differentials. These results carry over to the USD/GBP deprecation rate, but not for the USD/DM/EUR or USD/JPY. ${ }^{6}$ Indeed the estimates of $a_{1}^{\mathrm{T}}$ and $a_{1}^{\mathrm{V}}$ show that expectations concerning future net export growth and return differentials are more closely correlated with expected deprecation of the dollar against the pound, than against a broad basket of currencies.

Another notable feature of the results in Table 5 concerns the similarity between the estimates of $a_{1}^{\mathrm{T}}$ and $a_{1}^{\mathrm{V}}$. The variations in $\widehat{n x a}_{t}^{\mathrm{T}}$ and $\widehat{n x a}_{t}^{\mathrm{V}}$ are highly correlated over our sample period so it is impossible to identify whether expected future depreciation rates are more strongly correlated with forecasts of future net export growth or return differentials. As a consequence, $n x a_{t}$ has the same forecasting power for future depreciation rates as the Trade and Valuation components. This can be clearly seen from the estimates of $a_{1}$ in the right hand columns of the table. These estimates are approximately half the size of the estimated values for $a_{1}^{\mathrm{T}}$ and $a_{1}^{\mathrm{V}}$, but the $R^{2}$ statistics for regression (33) are roughly the same.

The last row of Table 5 provides another perspective on our findings. Since $\widehat{n x a}_{t}^{\mathrm{v}}$ comprises the present

\footnotetext{
${ }^{6}$ Conventional inference concerning the coefficients in forecasting regressions can be unreliable when the forecasting (RHS) variable is very persistent and has innovations that the highly negatively correlated with forecast (LHS) variable. Here, $n x a$, $\widehat{n x a}_{t}^{\mathrm{T}}$ and $\widehat{n x a}_{t}^{\mathrm{V}}$ all display a good deal of persistence, so the reliability of the standard errors reported in Table 5 is a potential issue. Campbell and Yogo (2006) design a simple pretest to determine if conventional t-test on the coefficients are invalid and develop an efficient test of predictability (the Bonferroni Q test) that corrects this problem. When we run the pretest we find that the correlations between most depreciation rates and innovations to the forecasting variables are insufficient to invalidate conventional t-tests. The one exception is the USD/GBP depreciation rate. When the Bonferroni Q test is run for this depreciation rate, we reject the null of non-predictability at the $5 \%$ level for each of the six forecasting regressions shown in Table 5.
} 
Table 5: Forecasting with Measures of the U.S. External Position

\begin{tabular}{|c|c|c|c|c|c|c|}
\hline \multirow[b]{2}{*}{ Horizon } & \multicolumn{2}{|c|}{ (i) $\widehat{n x a}_{t}^{\mathrm{T}}$} & \multicolumn{2}{|c|}{ (ii) $\widehat{n x a}_{t}^{\mathrm{V}}$} & \multicolumn{2}{|c|}{ (iii) $n x a_{t}$} \\
\hline & 1 & 4 & 1 & 4 & 1 & 4 \\
\hline Trade Weighted & $\begin{array}{c}-0.033^{* *} \\
(0.018)\end{array}$ & $\begin{array}{c}-0 \cdot 034^{* *} \\
(0 \cdot 014)\end{array}$ & $\begin{array}{c}-0 \cdot 028^{* *} \\
(0 \cdot 015)\end{array}$ & $\begin{array}{c}-0 \cdot 029^{* *} \\
(0 \cdot 012)\end{array}$ & $\begin{array}{c}-0.015^{* *} \\
(0.008)\end{array}$ & $\begin{array}{c}-0 \cdot 016^{* *} \\
(0 \cdot 007)\end{array}$ \\
\hline$R^{2}$ & 0.022 & $0 \cdot 076$ & $0 \cdot 022$ & 0.078 & $0 \cdot 022$ & $0 \cdot 076$ \\
\hline USD/DM & $\begin{array}{c}-0 \cdot 048 \\
(0 \cdot 031)\end{array}$ & $\begin{array}{r}-0.045^{*} \\
(0.024)\end{array}$ & $\begin{array}{r}-0.042 \\
(0.027)\end{array}$ & $\begin{array}{r}-0.039^{*} \\
(0.020)\end{array}$ & $\begin{array}{r}-0.022 \\
(0 \cdot 014)\end{array}$ & $\begin{array}{r}-0 \cdot 020^{*} \\
(0 \cdot 011)\end{array}$ \\
\hline$R^{2}$ & 0.015 & 0.052 & 0.016 & 0.053 & $0 \cdot 015$ & 0.052 \\
\hline USD/GBP & $\begin{array}{c}-0.063^{* *} \\
(0.025)\end{array}$ & $\begin{array}{c}-0 \cdot 069^{* * *} \\
(0 \cdot 022)\end{array}$ & $\begin{array}{c}-0 \cdot 053^{* *} \\
(0 \cdot 021)\end{array}$ & $\begin{array}{c}-0 \cdot 058^{* * *} \\
(0 \cdot 019)\end{array}$ & $\begin{array}{c}-0.029^{* *} \\
(0.011)\end{array}$ & $\begin{array}{c}-0 \cdot 031^{* * *} \\
(0 \cdot 010)\end{array}$ \\
\hline$R^{2}$ & $0 \cdot 037$ & $0 \cdot 149$ & $0 \cdot 036$ & $0 \cdot 148$ & $0 \cdot 036$ & $0 \cdot 148$ \\
\hline USD/JPY & $\begin{array}{c}-0.019 \\
(0.028)\end{array}$ & $\begin{array}{c}-0.013 \\
(0.024)\end{array}$ & $\begin{array}{c}-0.017 \\
(0.025)\end{array}$ & $\begin{array}{c}-0.013 \\
(0 \cdot 020)\end{array}$ & $\begin{array}{c}-0.009 \\
(0.013)\end{array}$ & $\begin{array}{c}-0 \cdot 006 \\
(0 \cdot 011)\end{array}$ \\
\hline$R^{2}$ & 0.002 & 0.004 & $0 \cdot 003$ & $0 \cdot 005$ & $0 \cdot 002$ & $0 \cdot 004$ \\
\hline NFA Returns & $\begin{array}{r}-0.025^{*} \\
(0.014)\end{array}$ & $\begin{array}{c}-0 \cdot 030^{* *} \\
(0 \cdot 012)\end{array}$ & $\begin{array}{r}-0.021^{*} \\
(0 \cdot 012)\end{array}$ & $\begin{array}{c}-0 \cdot 025^{* *} \\
(0 \cdot 010)\end{array}$ & $\begin{array}{r}-0.011^{*} \\
(0.006)\end{array}$ & $\begin{array}{c}-0 \cdot 014^{* *} \\
(0 \cdot 006)\end{array}$ \\
\hline$R^{2}$ & 0.026 & $0 \cdot 110$ & $0 \cdot 026$ & $0 \cdot 111$ & 0.025 & $0 \cdot 109$ \\
\hline
\end{tabular}

Notes: The table reports the estimated slope coefficients, standard errors in parenthesis, and $R^{2}$ statistics from regressions (28) - (33) in panels (i) - (iii) for depreciation rates and return differentials computed over horizons $k$ of 1 and 4 quarters. Standard errors allow for the presence of an $\operatorname{MA}(k-1)$ process in the regression residuals and sampling variation in the RHS variables in panels (i) and (ii). Statistical significance at the 10,5 , and 1 percent level is indicated by "**", "*** and "***", respectively.

value of expected future return differentials, we should expect to find that $\widehat{n x a}_{t}^{\mathrm{V}}$ has forecasting power for the actual differential, and that the power increases with the horizon $k$. This is indeed the case. Our estimates also show that the trade and valuation components have a similar degree of forecasting power for (some) dollar depreciation rates as they do for return differentials.

The results in Table 5 show how variations in the U.S. external position preceded changes in the rate of real dollar depreciation over the past 35 years. We now use these results to estimate the anticipated real depreciation of the dollar associated with the anticipated adjustment path for the U.S. external position shown in Figure 6. Specifically, we use our model forecasts to compute

$$
\widehat{\mathbb{E}}_{T} \varepsilon_{j, T+k}=\sum_{i=1}^{k} \widehat{\mathbb{E}}_{T} \Delta \varepsilon_{j, t+i}+\varepsilon_{j, T}=\hat{a}_{1} \sum_{i=0}^{k-1} \widehat{\mathbb{E}}_{T} n x a_{T+i}+\varepsilon_{j, T},
$$

where $\widehat{\mathbb{E}}_{T} n x a_{T+i}$ is the expected adjustment path plotted in Figure 6 and $\hat{a}_{1}$ is the estimated slope coefficient from regression (33). As a robustness check we also compute $\widehat{\mathbb{E}}_{T} \varepsilon_{j, T+k}$ using the paths for the trade and valuation components, $\widehat{\mathbb{E}}_{T} n x a_{T+i}^{\mathrm{T}}$ and $\widehat{\mathbb{E}}_{T} n x a_{T+i}^{\mathrm{V}}$, and the estimates of $a_{1}^{\mathrm{T}}$ and $a_{1}^{\mathrm{V}}$ from (28) and (32).

Figure 7 plots the expected future paths for the trade-wieghted real dollar exchange rate, and the real 


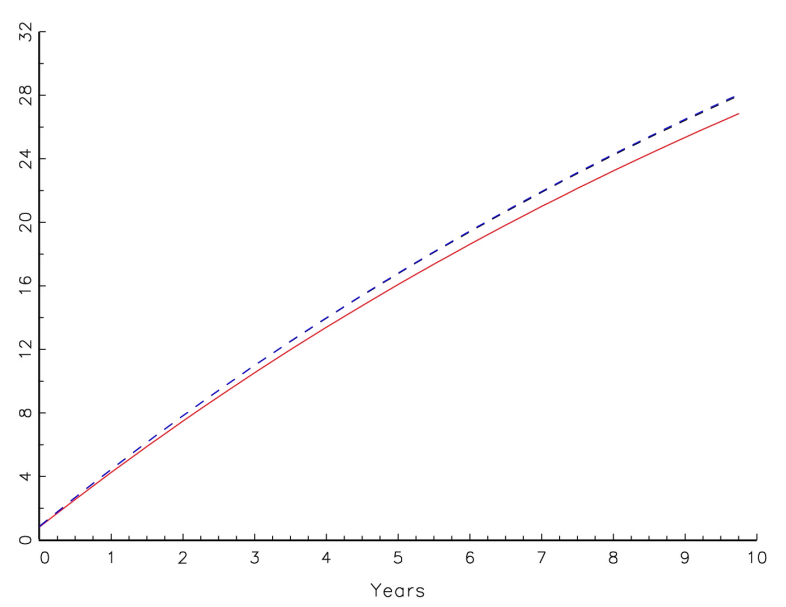

A: Trade-Weighted

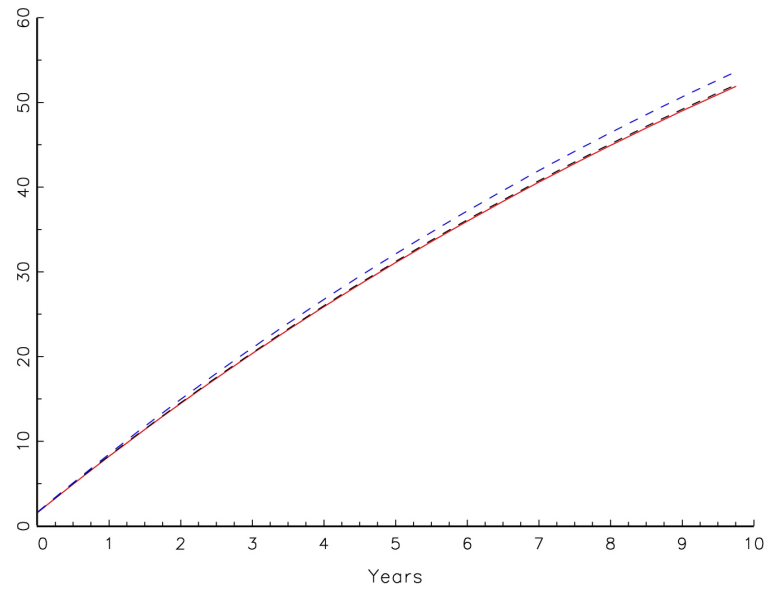

B: USD/GBP

Figure 7: Expected Real Depreciation Paths using $\widehat{\mathbb{E}}_{T} n x a_{T+k}-$ red, $\widehat{\mathbb{E}}_{T} n x a_{T+k}^{\mathrm{T}}$ - dashed blue, $\widehat{\mathbb{E}}_{T} n x a_{T+k}^{\mathrm{V}}$-dashed black

dollar pound exchange rate implied by the anticipated external adjustment path over a 10 year horizon starting in 2008:III. (We normalize the real exchange rates in 2008:III to unity, to facilitate comparisons between the plots.) Clearly, the anticipated adjustment path is associated with a very strong real depreciation of the dollar. In both cases there is very little difference between the exchange-rate expectations using the anticipated path for $n x a_{t}$, and those using the paths for the trade and valuation components. According to these calculations, over the first decade of adjustment the dollar is expected to depreciate by approximately 30 percent against a trade-weighted index for foreign currencies and by more than 50 percent again the pound. Of course, these plots are based on estimates for the future adjustment path and the slope coefficients in (28) - (33), so they inevitably contain some sampling error. It is clear, nevertheless, that insofar as the historical relation between depreciation rates and measures of the U.S. external position continue to hold, agent's current expectations about the path of future adjustment must be associated with a steep and prolonged real depreciation of the dollar.

\section{Conclusion}

The requirements of international solvency link the external position of any country to expectations concerning future trade flows and returns on its foreign assets and liabilities. The present value model developed in this paper embeds these solvency restrictions in a framework that can be easily evaluated with econometric methods. When applied to the U.S., our model provides a detailed picture of how expectations concerning future returns and trade flows have evolved as the U.S. external position deteriorated. This analysis provides us with estimates of how the U.S. external position will adjust in the future. These estimates suggest that the anticipated path of adjustment back towards external balance will be extremely slow and involve a prolonged and significant real depreciation of the dollar.

Let us offer some perspective on our results. First, our estimated path for future external adjustment is derived from the historical relationships between the U.S. external position, trade flows and the returns on U.S. foreign asset and liability portfolios. Of course, there is no guarantee that the time series behavior 
of the variables in our VARs will be invariant to future policy changes in the U.S. or elsewhere, so our estimated adjustment paths are potentially vulnerable to the Lucas critique. That said, we believe it would be a mistake to ignore the paths we estimate. The fact that we are able to find a stable relation between the evolution of the U.S. external position and time series estimates of expected future trade flows and returns, suggests that policy changes during the past 35 years did not have first-order effects. Our estimated adjustment paths only loose their relevance if one can plausibly argue that prospective policy changes are quite unlike the major changes in monetary, fiscal, regulatory and exchange rate policy (e.g., the creation of the euro) that took place over the past 35 years.

The second perspective concerns our choice for $\rho$, the discount factor in the present value model. Our approach is to estimate a value for $\rho$ that best matches the historical behavior of the U.S. external position with VAR estimates of expected future trade flows and returns in a framework where the U.S. is expected to honor its future international obligations. From a theoretical perspective, $1-\rho$ should equal the steady state values of $\mathfrak{M}_{t} / R_{t}^{\mathrm{FA}} F A_{t-1}$ and $\mathfrak{X}_{t} / R_{t}^{\mathrm{FL}} F L_{t-1}$, so ideally our estimates for $\rho$ should also be consistent with the sample averages of these ratios. This is not the case. The sample averages imply a lower value for $\rho$ than our estimate. Consequently, if we calibrate $\rho$ to be consistent with these sample averages, our VAR estimates for expected future trade flows and returns cannot account for all the historical variations in the U.S. external position. We do not view this as evidence against our present value model. It is unlikely that these averages are precise estimates of steady state values given the well-documented growth in international trade and financial flows over our sample period. The question of whether the value for $\rho$ we estimate is consistent with reasonable steady state values for $\mathfrak{M}_{t} / R_{t}^{\mathrm{FA}} F A_{t-1}$ and $\mathfrak{X}_{t} / R_{t}^{\mathrm{FL}} F L_{t-1}$ requires a theoretical model that pins down these ratios in terms of precisely estimated parameters. To our knowledge, no such model yet exists.

Finally, we should stress that our analysis is based on the assumption that the U.S. external position is on a sustainable path. Ultimately, there is no way to test whether this assumption is true with the available data. What we have shown is that it is possible to understand the historical deterioration in the U.S. external position in terms of changing expectations regarding future trade flows and returns, and that these expectations imply that there is an anticipated path of adjustment that will restore the U.S. to external balance. We view this finding as starting point for more detailed analysis of how external adjustment could take place.

\section{References}

Bertaut, C. and R. Tryon (2007). Monthly estimates of us cross-border securities positions. FRB International Finance Discussion Papers No. 910.

Campbell, J. and R. Shiller (1987). Cointegration and tests of present value models. The Journal of Political Economy 95(5).

Campbell, J. and L. Viceira (2002). Strategic Asset Allocation: Portfolio Choice for Long-Term Investors. Oxford University Press.

Campbell, J. and M. Yogo (2006). Efficient tests of stock return predictability. Journal of Financial Economics 81(1), 27-60. 
Curcuru, S., T. Dvorak, and F. Warnock (2008). 'cross-border returns differentials'. Quarterly Journal of Economics 123.

Forbes, K. (2009). Why do foreigners invest in the united states? Journal of International Economics.

Gourinchas, P. and H. Rey (2005). From world banker to world venture capitalist: Us external adjustment and the exorbitant privilege. NBER Working Paper.

Gourinchas, P. and H. Rey (2007). International financial adjustment. Journal of Political Economy 115(4), 665-703.

Lane, P. and G. Milesi-Ferretti (2001). The external wealth of nations: measures of foreign assets and liabilities for industrial and developing countries. Journal of international Economics 55(2), 263-294.

Lane, P. and G. Milesi-Ferretti (2004). The transfer problem revisited: Net foreign assets and real exchange rates. Review of Economics and Statistics 86(4), 841-857.

Lane, P. and G. Milesi-Ferretti (2007). The external wealth of nations mark ii: Revised and extended estimates of foreign assets and liabilities, 1970-2004. Journal of International Economics 73(2), 223250.

Newey, W. and K. West (1987). A simple, positive semi-definite, heteroskedasticity and autocorrelation consistent covariance matrix. Econometrica 55(3), 703-708.

Tille, C. (2003). The impact of exchange rate movements on us foreign debt. Current Issues in Economics and Finance 9(1), 1-7.

White, H. (1980). A heteroskedasticity-consistent covariance matrix estimator and a direct test for heteroskedasticity. Econometrica: Journal of the Econometric Society, 817-838.

\section{Appendix}

\subsection{Bootstrap Procedure:}

To compute the boostrap distribution for the Wald statistics we repeat the following steps:

1. We draw a boostrap sample of errors from the estimated VAR residuals equal to the length of our data same $T$, and construct the sequence of error terms for the companion form: $\left\{\widetilde{U}_{t}\right\}_{t=1}^{T}$. We also draw a bootstrap sample from the estimated specification errors using the estimated value for $\rho, \hat{\rho}:\left\{\widetilde{\xi}_{t}\right\}_{t=1}^{T}$.

2. We recursively compute a bootstrap sample for $\left\{\widetilde{Z}_{t}\right\}_{t=1}^{T}$ from $\widetilde{Z}_{t}=\widehat{A} \widetilde{Z}_{t-1}+\widetilde{U}_{t}$ with $\widetilde{Z}_{0}$ fixed at a vector of zeros. As part of this procedure, in each period $t$ we replace the third element in $\widetilde{Z}_{t}$ (i.e., the unrestricted value for $\left.n x a_{t}\right)$ with $n x a(\hat{\rho})_{t}=\widetilde{r}_{t}^{\mathrm{NFA}}+\Delta \widetilde{n x}_{t}+(1 / \hat{\rho}) n x a(\hat{\rho})_{t-1}+\widetilde{\xi}_{t}$, where $\widetilde{r}_{t}^{\mathrm{NFA}}$ and $\Delta \widetilde{n x}_{t}$ are the first and second elements of $\widetilde{Z}_{t}$. Rewriting this equation and iterating forward gives $n x a(\hat{\rho})_{t}=-\sum_{i=1}^{\infty} \hat{\rho}^{i}\left(\widetilde{r}_{t+i}^{\mathrm{NFA}}+\Delta n x_{t+i}+\widetilde{\xi}_{t+i}\right)$. By construction, $\mathbb{E}\left[\widetilde{\xi}_{t+i} \mid \widetilde{Z}_{t}\right]=0$ and $\mathbb{E}\left[\widetilde{r}_{t+i}^{\mathrm{NFA}}+\Delta n x_{t+i} \mid \widetilde{Z}_{t}\right]=$ $\left(\imath_{r}+\imath_{n x}\right) \widehat{A}^{i} \widetilde{Z}_{t}$ for $i>0$, so this expression implies that $n x a(\hat{\rho})_{t}=-\left(\imath_{r}+\imath_{n x}\right) \hat{\rho} \widehat{A}(I-\hat{\rho} \widehat{A})^{-1} \widetilde{Z}_{t}$.

3. We estimate the VAR using $\left\{\widetilde{Z}_{t},\right\}_{t=1}^{T}$ and use the estimates to compute the companion matrix in (16), $\widetilde{A}$. 
4. We compute a value for $\rho, \tilde{\rho}$, that minimizes the sample variance of the specification error,

$$
\xi_{t}=\widetilde{n x a}_{t}-\widetilde{n x a}_{t}^{\mathrm{V}}-\widetilde{n x a}_{t}^{\mathrm{T}}=\left[\imath_{n x a}+\left(\imath_{r}+\imath_{n x}\right) \rho \widetilde{A}(I-\rho \widetilde{A})^{-1}\right] \widetilde{Z}_{t} .
$$

5. Finally, we use the boostrap sample $\left\{\widetilde{Z}_{t},\right\}_{t=1 t=1}^{T}$ to compute the Wald statistic for the null

$$
\imath_{n x a}=-\left(\imath_{r}+\imath_{n x}\right) \tilde{\rho} \widetilde{A}(I-\tilde{\rho} \widetilde{A})^{-1} .
$$

Steps 1 - 5 are repeated 5000 times to build the bootstrap distribution for the Wald statistic for $\rho=0.993$. The p-values report the fraction of our 5000 trails that generate Wald statistics larger than the value we compute in our data.

\subsection{Derivations}

To derive (24), we iterate (10) forward $k$ periods, to get

$$
n x a_{t}=-\sum_{i=1}^{k} \rho^{i} \mathbb{E}_{t}\left(r_{t+i}^{\mathrm{NFA}}+\Delta n x_{t+i}\right)+\rho^{k} \mathbb{E}_{t} n x a_{t+k}
$$

Subtracting $\rho^{k} n x a_{t}$ from both sides and re-arranging produces

$$
\begin{aligned}
\mathbb{E}_{t} \Delta^{k} n x a_{t+k} & =\rho^{-k} \sum_{i=1}^{k} \rho^{i} \mathbb{E}_{t}\left(r_{t+i}^{\mathrm{NFA}}+\Delta n x_{t+i}\right)+\rho^{-k}\left(1-\rho^{k}\right) n x a_{t} \\
& =\rho^{-k} \sum_{i=1}^{k} \rho^{i} \mathbb{E}_{t}\left(r_{t+i}^{\mathrm{NFA}}+\Delta n x_{t+i}\right)-\rho^{-k}\left(1-\rho^{k}\right) \sum_{i=1}^{\infty} \rho^{i} \mathbb{E}_{t}\left[r_{t+i}^{\mathrm{NFA}}+\Delta n x_{t+i}\right] . \\
& =\sum_{i=1}^{k} \rho^{i} \mathbb{E}_{t}\left(r_{t+i}^{\mathrm{NFA}}+\Delta n x_{t+i}\right)-\left(1-\rho^{k}\right) \sum_{i=k+1}^{\infty} \rho^{i-k} \mathbb{E}_{t}\left[r_{t+i}^{\mathrm{NFA}}+\Delta n x_{t+i}\right] .
\end{aligned}
$$

To derive (29), let $\Lambda_{t}^{\mathrm{FA}}=\left[\lambda_{1, t}^{\mathrm{FA}}, \ldots \lambda_{j, t}^{\mathrm{FA}}, \ldots ., 1-\sum_{j} \lambda_{j, t}^{\mathrm{FA}}\right]^{\prime}$ and $\Lambda_{t}^{\mathrm{FL}}=\left[\lambda_{1, t}^{\mathrm{FL}}, \ldots \lambda_{j, t}^{\mathrm{FL}}, \ldots ., 1-\sum_{j} \lambda_{j, t}^{\mathrm{FL}}\right]^{\prime}$ denote the vectors of currency shares in the U.S. foreign asset and liabilities portfolios, with corresponding vectors of $\log$ returns, $\mathfrak{r}_{t+1}^{\mathrm{FA}}=\left[\hat{\mathfrak{r}}_{1, t+1}^{\mathrm{FA}}+\Delta \varepsilon_{1, t+1}, \ldots \hat{\mathbf{r}}_{j, t+1}^{\mathrm{FA}}+\Delta \varepsilon_{j, t+1}, \ldots ., \mathfrak{r}_{t+1}^{\mathrm{FA}}\right]^{\prime}$ and $\mathfrak{r}_{t+1}^{\mathrm{FL}}=\left[\hat{\mathfrak{r}}_{1, t+1}^{\mathrm{FL}}+\Delta \varepsilon_{1, t+1}, \ldots \hat{\mathfrak{r}}_{j, t+1}^{\mathrm{FL}}+\right.$ $\left.\Delta \varepsilon_{j, t+1}, \ldots ., \mathbf{r}_{t+1}^{\mathrm{FL}}\right]^{\prime}$. Campbell and Viceira (2002)) show that the log return on foreign assets and liabilities are well approximated by

$$
\begin{aligned}
r_{t+1}^{\mathrm{FA}} & =\left(\Lambda_{t}^{\mathrm{FA}}\right)^{\prime} \mathfrak{r}_{t+1}^{\mathrm{FA}}+\frac{1}{2}\left(\Lambda_{t}^{\mathrm{FA}}\right)^{\prime}\left(\operatorname{diag}\left(\Sigma_{t}^{\mathrm{FA}}\right)-\Sigma_{t}^{\mathrm{FA}} \Lambda_{t}^{\mathrm{FA}}\right), \quad \text { and } \\
r_{t+1}^{\mathrm{FL}} & =\left(\Lambda_{t}^{\mathrm{FL}}\right)^{\prime} \mathfrak{r}_{t+1}^{\mathrm{FL}}+\frac{1}{2}\left(\Lambda_{t}^{\mathrm{FL}}\right)^{\prime}\left(\operatorname{diag}\left(\Sigma_{t}^{\mathrm{FL}}\right)-\Sigma_{t}^{\mathrm{FA}} \Lambda_{t}^{\mathrm{FL}}\right)
\end{aligned}
$$

Combing these approximations with the identity, $r_{t+1}^{\mathrm{NFA}} \equiv r_{t+1}^{\mathrm{FA}}-r_{t+1}^{\mathrm{FL}}$, gives equation (29) with $\Omega_{t}^{\mathrm{FA}}=$ $\frac{1}{2}\left(\Lambda_{t}^{\mathrm{FA}}\right)^{\prime}\left(\operatorname{diag}\left(\Sigma_{t}^{\mathrm{FA}}\right)-\Sigma_{t}^{\mathrm{FA}} \Lambda_{t}^{\mathrm{FA}}\right)$ and $\Omega_{t}^{\mathrm{FL}}=\frac{1}{2}\left(\Lambda_{t}^{\mathrm{FL}}\right)^{\prime}\left(\operatorname{diag}\left(\Sigma_{t}^{\mathrm{FL}}\right)-\Sigma_{t}^{\mathrm{FA}} \Lambda_{t}^{\mathrm{FL}}\right)$. 